\title{
A scenario-based robust time-cost tradeoff model to handle the effect of COVID-19 on supply chains project management
}

\author{
Seyed Hossein Razavi Hajiagha' ${ }^{1} \cdot$ Hannan Amoozad Mahdiraji ${ }^{2,3} \cdot$ Maryam Behnam $^{3} \cdot$ Boshra Nekoughadirli $^{3}$. \\ Rohit Joshi ${ }^{4}$
}

Received: 15 March 2021 / Revised: 30 April 2021 / Accepted: 13 May 2021 / Published online: 21 May 2021

(c) The Author(s), under exclusive licence to Springer Science+Business Media, LLC, part of Springer Nature 2021

\begin{abstract}
The COVID-19 pandemic outbreak deeply impressed supply chains in different aspects. In response to this unexpected situation, supply chain managers have decided to recover and reinforce their supply chains. Considering the expanse of these decisions, project management principle and tools seems inevitable to successfully manage the transformation from before pandemic to post-pandemic supply chains (SCs). In this study, the problem of time-cost tradeoff is extended to time, cost, and risk tradeoff. The risk factor is considered to convey the uncertainty arising from the COVID-19 pandemic situation. Since projects are affected by the level of pandemic expansion and different countries ruled out various quarantine policies (isolation, quarantine, social distancing, and lock-down), the tradeoff problem is influenced accordingly. Therefore, a scenariobased robust optimization model is proposed to deal with time, cost, and risk tradeoff problems to reflect the effects of the global pandemic of COVID-19 on managing projects in supply chains. In addition, various quarantine policies (isolation, quarantine, social distancing, and lock-down) as a prevalent response to the pandemic have been investigated separately. To illustrate the model, a real-world case study in the emerging economy of Iran is examined using the proposed approach. The results indicated that supply chain managers can use the designed model and approach as a tool for a flexible and adaptable decision-making framework dealing with a global pandemic such as COVID-19.
\end{abstract}

Keywords COVID-19 pandemic $\cdot$ Supply chain management (SCM) $\cdot$ Project management (PM) $\cdot$ Time-cost-risk tradeoff (TCRT) · Quarantine level · Robust optimization

\section{Introduction}

Hannan Amoozad Mahdiraji

hannan.amoozadmahdiraji@dmu.ac.uk; h.amoozad@ut.ac.ir

Seyed Hossein Razavi Hajiagha

h.razavi@khatam.ac.ir

Maryam Behnam

maryam.behnam97@ut.ac.ir

Boshra Nekoughadirli

boshra.nekoo@ut.ac.ir

Rohit Joshi

rj@iimshillong.ac.in

1 Department of Management, Faculty of Management and Finance, Khatam University, Tehran, Iran

2 Leicester Castle Business School, Faculty of Business and Law, De Montfort University, Leicester, UK

3 Faculty of Management, University of Tehran, Tehran, Iran

4 Department of Operations Management, Indian Institute of Management Shillong, Shillong, India
Facing a novel widespread pandemic caused by the SARSCoV-2 virus, known as the COVID-19 pandemic, global supply chains are suffering from the most disastrous disruption in recent decades (Karmaker et al. 2021). The connection among supply chains, manufacturing industries, and international markets aggravates negative effects globally (Chena et al. 2019). As Ivanov and Dolgui (2020) discussed, the COVID-19 pandemic has substantially affected the global economy, demolished several industries as well (Belhadi et al. 2021). Nearly $6 \%$ and $1 \%$ decrease in the advanced and developing economies is estimated by International Monetary Fund (IMF), respectively (Karmaker et al. 2021). As reported COVID-19 had considerable negative effects on 94\% of 1000 companies reviewed by this organization (Baz and Ruel 2021). Moreover, supply flow and demand have been negatively affected by the COVID-19 pandemic directly in both local and global markets as these impacts 
can cause ripple effects by spreading throughout the entire supply chain. (Baz and Ruel 2021; Chena et al. 2019). Incidents like COVID-19 force companies to try to determine and assess potential risks that their supply chain might face (Sabouhi et al. 2018). Risk can be considered a major factor in making different decisions (Garousi Mokhtarzadeh et al. 2020a, b). According to Sabouhi et al. (2018), there are two main types of risks entailed in the supply chain network context.

Operational risks. Ingrained uncertainties are caused by mundane disturbances with high frequency in nature and small interruptions.

Disruption risks. low-frequent disruptions are usually caused by disasters and large-scale threats inflicting considerable damages on the whole supply chain (Sabouhi et al. 2018; Ivanova 2020).

With the emerge of coronavirus from Wuhan, China, socalled the factory of the world, immediate distractions in Chinese exports have challenged supply availability on a global scale (Ivanova 2020). This has extended the COVID19 pandemic from a health crisis to an economic catastrophe where firms and supply chains struggle to form COVID-19friendly systems which can effectively help them to survive this disaster (Karmaker et al. 2021). Therefore, enhancing supply chain resilience regarding pandemics like COVID-19 has become a popular research topic to improve the supply chain's capability of resistance in cases of massive disruptions (Belhadi et al. 2021). Jabbour et al. (2020) point out as this outbreak proved the importance of supply chains to the global economy, there is a need for regenerated approaches to supply chain management resilience. Bearing that in mind, the COVID-19 pandemic has brought a good learning opportunity to improve resilient practices and dynamism in supply chains to make them more capable of dealing with disruptive events (Hoek 2020).

Observing this issue through the lens of operation, the definition of resilience can be "an organism in which systems adjust to disruptions" and must be prepared, responsive, and modifying (Prasad et al. 2019). Needless to say, supply chain networks are opposed to many changes, community policies, and unexpected events which may lead to disruptions; consequently, they should be ready to be challenged by serial changes in advance. Hence, conducting resilience principles enable them to overcome obstacles in this spiral way. Resilience helps systems to get through disruption times and assure that they return to a stable condition at the postdisaster stage (Mehrjerdi and Shafiee 2021). In the same sense, academic researchers have shown interest in terms of resilience in projects, aiming to perceive the ability of different systems involving in projects to adequately perform in times of unpredictable imposed changes (Naderpajouh et al. 2020a, b). Project management practices desire to assure that the project can meet allocated time and budget. In this environment, one of the most important aspects of project management is uncertainty, which means dealing with problems where possible events are known without predetermined probability (Mensah et al. 2021) which can significantly challenge project objectives and cause many disturbances (Torabi Yeganeh and Zegordi 2020). Same as before, this special case of the COVID-19 pandemic is also one of the most recent examples of a disaster directly affecting the resilience of projects and operations performance globally (Naderpajouh et al. 2020a, b). However, the disaster management process (i.e. attempts made during all levels of disaster to do damage control to the economy) can be pictured about a project consisting of specific products, time restrictions, and resource constraints. Therefore, as disaster management resembles large-scale public project management, advanced project management approaches may be beneficial in all phases of disaster management (Prasad et al. 2019).

Correspondingly, with all the challenges that firms and supply chains are confronting as a result of this pandemic, there is a need for a better understanding of the nature and role of projects and changes in supply chains since they are happening simultaneously in the context of disasters. (Pádár et al. 2017). In this regard, a few studies have considered project management and resilience aspects which were not focused directly on supply chain practices. For instance, the effect of project management and stakeholder engagement on disaster resilience has been studied (Crawford et al. 2013; Mokhtarzadeh et al. 2018). While Prasad et al. (2019) discussed that disaster-oriented project management can generally enhance disaster resilience, their studies excluded the supply chain context. Moreover, due to different forces like demand fluctuations for a variety of goods and outsourcing, SCs have become more complex in terms of processes and tasks (Gaudenzi and Christopher 2015). Since there has been a rise in the number of new and non-repetitive processes and activities in this context, Gaudenzi and Christopher (2015) argued that SCM has also turned to project management. Nonetheless, the effectiveness of applying PM approaches to SCM still has not been widely discussed.

Accordingly, considering that project management is vital in term of managing the supply chain especially on the formation and arrangement of supply chains' strategy, it's getting more important to discern the performance of project management while supply chain dynamism is facing and adapting to new situations; in this special case, we are dealing with COVID-19. (Frederico et al. 2021). The importance of project management in SCM can be characterized considering its role in initiating and directing the SCM initiative dealing with disruptions (Smith and Offodile 2007). Projects like new product development, adopting new 
technologies and strategies, supplier replacement, etc. can be considered as some of the responses that SCs pursue to become more resilient. Project management is a fundamental consideration for the successful management of SC initiatives (Ayers 2009). Ayers (2009) pointed out a brilliant perspective on observing SCM from the viewpoint of project management. In this perspective, he considered SCM as a project and proposed to apply the principles of project management. Taking a project management approach to enhancing the capabilities of a supply chain can be considered as a way to handle the complexity and time-based competitiveness, meaning a corporate ability to provide customers with services and products meeting their expectations (Sukumar et al. 2020), in the current global markets becoming more difficult by the appearance of different crises (Gaudenzi and Christopher 2015). This paper aims to propose a robust time-cost-risk tradeoff to handle and manage the supply chain projects in a more resilient model to alleviate the challenges arising from disruptions like the COVID-19 pandemic. It investigates different levels of quarantine, the most common response to the pandemic all over the world, as separate scenarios, then their impacts on different dimensions of the model are discussed. Generally speaking, borrowing a project management approach dealing with crisis and according to project management life cycle (PMLC) approach consisting scope, plan, launch, monitor and control, and close project (Wysocki 2013) is followed to define appropriate projects setting to compensate the COVID-19 pandemic effects and then proposing a time-schedule based on the uncertainty of the pandemic situation.

Considering that the advertising industry is known as a worldwide, upscale business linking manufacturers and customers, this paper has appointed its case study to this field. In 2018, the global spending on media advertising has been estimated at nearly $\$ 629$ billion with about a $44 \%$ share of digital advertising, reported by the eMarketer research group. Same as so many other industries, the COVID-19 pandemic has interrupted the steadily increasing trend of spending on advertising all over the world. However, a growth track in 2021 has been predicted leading to surpass $\$ 630$ billion spendings for advertisement in 2024. As Statista reported, the spending on advertising significantly increased from 402 billion dollars in the year 2012 to 649 in 2021 (Guttmann 2021). This amount of increase necessitates the appropriate readiness of the firms toward future products (Garousi Mokhtarzadeh et al. 2020a, b). Thus, the presented model has been applied to data exploited from an advertising company that managed to perform a supply chain re-engineering project on their SC. This case study has a chain of activities that are connected tightly and are tied in each level of the supply chain which makes them face several challenges during variant levels of the pandemic. To survive the massive disruption caused by a coronavirus, the studied firm has decided to conduct a project to preserve their SC which will be discussed in the next following sections.

In the current study, an axiomatic research methodology is followed to obtain a solution for the supply chain time, cost, risk tradeoff problem (Bertrand and Fransoo 2002). The remainder of the paper is organized as follows. First, a review of the related literature is given in Sect. 2. Subsequently, the considered problem is defined formally and the mathematical model along with its solving approach is described in Sect. 3. Next, an application of the proposed model in a supply chain project responding to the pandemic effects and boosting supply chain resiliency is examined in Sect. 4 with a discussion on the proposed model results. Finally, the conclusion section with some clues for future researches is discussed in Sect. 5.

\section{Literature review}

The recent pandemic caused by COVID-19 explained how SCs suffer from low levels of resilience and disruptions that can blemish them on a global scale (Golan et al. 2020). The essential role of the SC for actively providing markets with goods and services has become lucid due to the current pandemic (Ivanov and Dolgui 2020). Resilience is a multi-faced and not yet standardized concept so that several definitions and assessment methods exist. Resilience is considered a concept that is not completely standardized, has several faces and is measured by multiple methods (Emanuele Bellini et al. 2021). During the pandemic, firms experienced issues handling the resilience concept due to the new situation and it's become the core part of supply chains (Ivanov 2021). SCs were tested regarding their resilience including their robustness, flexibility, and recovery ability in this erratic era. (Ivanov and Dolgui 2020). From an organizational viewpoint, supply chain resilience (SCR) is the ability of firms to smooth the impact of unexpected disturbances inside and outside of organizations employing operational resources (Wong et al. 2020). Researches in this field indicate that resilience spread over technical, economic, environmental, social, and political areas (Emenike and Falcone 2020). Needless to say, various definitions for resilience has been stated within the literature; nonetheless, the National Academy of Sciences (NAS) expresses that resilience can formulate and design how to take in and rescue from conflicting events while revising the system to keep up with changes which is the most integrated approach that can be assessable. (Golan et al. 2020).

As could be expected, researchers have been showing interest in terms of creating more resilient supply chains. As quantitative methods have been studied, systematic literature reviews on the analytical origins demonstrate that resilience can be static or dynamic (Wong et al. 2020). Hasani 
and Khosrojerdi (2016) used a mixed integer programming (MIP) model to study resilience in the concept of similar disruptions. Rezapour et al. (2017) expanded a resilient structure of an SC that can resist and repair itself swiftly. Three policies were examined to preserve emergency stock at the retailers, making extra capacity at the suppliers, and multisourcing. To achieve the most financially beneficial method and mitigation policies, they used a non-linear mixed-integer programming (MIP) model. Their study illustrated that the $\mathrm{SC}$ can be taken under control by risk mitigation policies, sustaining and improving SC's market share, and be useful for customers by placing retail prices in the market (Ivanov et al. 2017). In this perspective, Wong et al. (2020) explored performance outcomes under moderating effects of the SC disruptions using a theoretical method. They declared that supply chain resilience (SCR) is firmly correlated with risk management and operational performance. Relevant studies on this topic include a systematic review on quantitative SCR modeling, defining defense line and a new definition for SCR, based on the resilience capacity of SCs (Hosseinia et al. 2019); surveying SCR literature on resilience modeling and quantification to analyze and present the diversity of SCR applications (Golan et al. 2020); designing a riskresilient SC and proposing different resiliency strategies applying structural equation modeling (Baz and Ruel 2021); resilient supplier selection modeling and optimization for order allocation problem (Hosseini et al. 2019).

As managing the SC's disruption has become a hot topic recently, the COVID-19 pandemic disruption also becomes a new challenge, completely different from any ones seen before. The world and particularly SCs, still suffer from ambiguity and troubles caused by COVID-19. For example, some SCs had to switch between industries that might be the end of life for those businesses. (Ivanov and Dolgui 2020) As Walmart reported, various industries have been encountering massive panic shopping because of the COVID-19 pandemic. A study by The Chartered Institute of Procurement and Supply, on March 282020 indicates that $86 \%$ of SCs are influenced by the COVID-19 pandemic. Moreover, The Institute for Supply Management found out that during March the percent of firms with SC's changes increased from 80 to 95\% (Hoek 2020). In this field, Belhadia et al. (2020) have examined the upcoming influences on the SCs caused by this pandemic through an integrated approach. Their results announced visions about COVID-19 outbreak effects on the airline SC and automobile in this case. Hoek (2020) has debated the impact of fluctuations in supply, demand, and risks and the significant need for resilience in times of pandemics. Examining more closely, Ivanov (2020) conducted a simulation study, to forecast the consequences of the COVID19 pandemic affecting global SCs. In virtue of these experiences, not only researchers but also managers are craving for the development of resilience practices to prevent firms from disruption effects (Ivanov and Dolgui 2020).

Bearing those in mind, since SCs encompass key valueadding business processes, SCM can be defined as a solid combination of complicated and multidimensional temporary projects, which includes independent firms collaborating to provide customers with the desired value (Thomé et al. 2016). At the complexity level of SCs, projects can be effectively helpful to remain operational in times of crisis by enhancing the joint capabilities of the firms collaborating in the SC. Projects can reinforce all types of operations in a firm, which makes project resilience more essential for retaining competitive advantages. As a result, there is an opportunity to link traditional PM concepts like risk and uncertainty management to project resilience practices aiming at a complementary approach. In times of disruptions, the system's failure often starts at the level of individuals or team disruptions, that deluge up through processes and projects; however, the impacts are usually monitored at organizational, industrial, and societal levels (Chowdhury et al. 2020). Meanwhile, the dynamic and rapid nature of disruptions needing prompt response reveals the necessity of projects (Qin et al. 2021). Therefore, prior research pointing to individuals, teams, or organizations is required to be reconsidered at the project level.

Researchers interest in blending the resilience concept and projects has been revealed recently. Main PM concepts of risk and uncertainty have been studied in prior research aiming to discover the dimensions and role of risk and resilience (Naderpajouh et al. 2020a, b). In recent literature, Nachbagauer and Schirl-Boeck (2019) studied system theory and resilience in the context of megaprojects. They discussed that PM literature underestimated the role of risk and uncertainty while presenting a hierarchical planning and control-focused perspective. Other PM researches have pointed to PM concepts in the context of disaster resilience (Prasad et al., 2019); presenting conceptual frameworks for project resilience (Rahi 2019); analyzing the impact of resilience-related practices on project sustainability (Kazmi et al. 2018); enhancing project success possibility through risk management (Buganova and Simickova 2020). In a mildly more specialized viewpoint, Prasad et al. (2019) studied the applications of PM concepts and frameworks in the context of disaster resilience. They defined the relationship between external elements of the disaster management process and the internal characteristics of disaster project management. In the same sense, Einabadi et al. (2019) applied a fuzzy-DEA approach to analyze PM performance regarding resilience engineering and HSE factors. A lightly more specialized batch of research targets innovative (Oeij et al. 2017; Todt et al. 2019) and exploratory projects (Wied et al. 2020), aiming to discriminate flexible and creative organizing approaches (Naderpajouh et al. 2020a, b). 
As discussed, SCM and PM studies consider risk mitigation as the main role of resilience practices. The literature indicates a wide range of fields where the term resilience, has been used such as SCM, PM, strategic management, metallurgy, ecology, psychology, and safety engineering (Thomé et al. 2016; Mahmoudi et al. 2019). Previous researches regarding SCR and PM in the majority are qualitative including systematic reviews of the literature on resilience in the context of SC and PM independently, evaluating the impacts of disruptions on SCRM and project management resilience (PMR), the conceptual framework of $\mathrm{PM}$, applications of PM concepts in the context of disaster resilience, and so forth. A summary of reviewed literature is presented in Table 1 .

To provide a clear definition of the considered problem, the aim of supply chain project management is restated here. According to (Ayers 2009; Beheshti et al. 2016), supply chain project management aims to enable managers in developing and executing supply chain strategies using both SCM and project management. The necessity of adherence to project management practices is intensified during the pandemic situation. Some companies decided to made critical changes in their SCs, e.g. repurpose their production and operations, handling mismatch between demand and supply, the urgency of enhancing supply chain resiliency are some of these major shifts in SCs (Sharma et al. 2020). Considering agility as the ability to quickly respond to changes (Ulrich and Yeung 2019), it is evident that a successful SC required an agile shift in the strategies. Therefore, in defining a supply chain decision to change its strategy in the context of a project, it is inevitable to equip with project management tools for good management of SC projects. The Time-cost tradeoff problem (TCTP) is one of the well-known and widely applied problems of project management (Shahsavari Pour et al. 2012; Razavi Hajiagha et al. 2014). TCT aims to achieve a balanced set of a project's activities time and cost. Typically, TCTP models are classified into two scenarios including continuous and discrete models. In the continuous model, it is assumed that there is a continuous relationship between the time and cost of each activity. Considering a normal and crash time for the cost and time of activities, the model seeks to determine the optimal time and cost of activities between the normal and crash forms. On the other hand, in the discrete TCTP models, different modes of execution are assumed for each activity with different times and costs. The discrete model identified the best combination of activity modes (Son et al. 2013; Taghavifard et al. 2018).

Beyond the classic TCTP framework, the risk is another important aspect that must be considered in project management, especially during crises like the Covid-19 pandemic. Risk management significantly affects the project's success (de Carvalho and Rabechini Junior 2015; Muriana and Vizzini 2017). Considering the impact of the Covid-19 outbreak on logistic and supply chains, due to lockdown and its effects on demand and supply balance (Singh et al. 2020), the risk is an inevitable factor to be included in the resiliency of SC projects. A summary of recent studies about TCTP models and their extensions is illustrated in Table 2. Reviewing the studies, generally, the tradeoff problems deal with time-cost tradeoff while some studies consider other objectives, e.g., risk, quality, and sustainability-related measures. There is no majority between discrete or continuous tradeoff problems and different algorithms are proposed to solve the problems. About the uncertainty, a considerable part of studies formulated the tradeoff problems under certainty. However, it seems a meaningful desire toward stochastic programming, while fuzzy set theory and robust optimization are also considered. Note that, a majority of studies are also focused on construction projects as their case studies.

In line with previous researches presented in Table 1, to the best knowledge of the authors, none of the related literature considered the intersection of supply chain management and project management, especially regarding the COVID19 situation. Besides, while the impacts of disruptions like the COVID-19 pandemic on the supply chain process have been illustrated previously, time-cost tradeoff modeling has not been investigated to mitigate the unexpected risks. In this paper, a robust discrete time-cost-risk tradeoff model is proposed to manage the supply chain projects in a more resilient mode regarding the environmental risks due to the Covid-19 pandemic. From a theoretical perspective, the risk factor is rarely considered in the discrete tradeoff problems. The main advantage of the proposed model is to consider the risks and variations of the pandemic in scheduling the supply chain problems. Moreover, since stochastic and fuzzy methods require determinations of a statistical or membership function, robust optimization can solve the uncertainty caused by a pandemic situation without requiring any pre-determined functional form. Therefore, the main contributions of the current study can be summarized as below:

- Formulating the time, cost, and risk tradeoff problems in the context of supply chain management projects;

- Proposing a scenario-based robust optimization model to deal with different conditions due to pandemic outbreak level;

- Analyzing the impact of the pandemic outbreak based on the level of quarantine being ruled out on the time, cost, and risks of the supply chain projects.

\section{Modeling}

the problem of optimizing the time-cost-risk tradeoff in an SC project to achieve more resilient project management responding to the Covid-19 pandemic-related risks is 


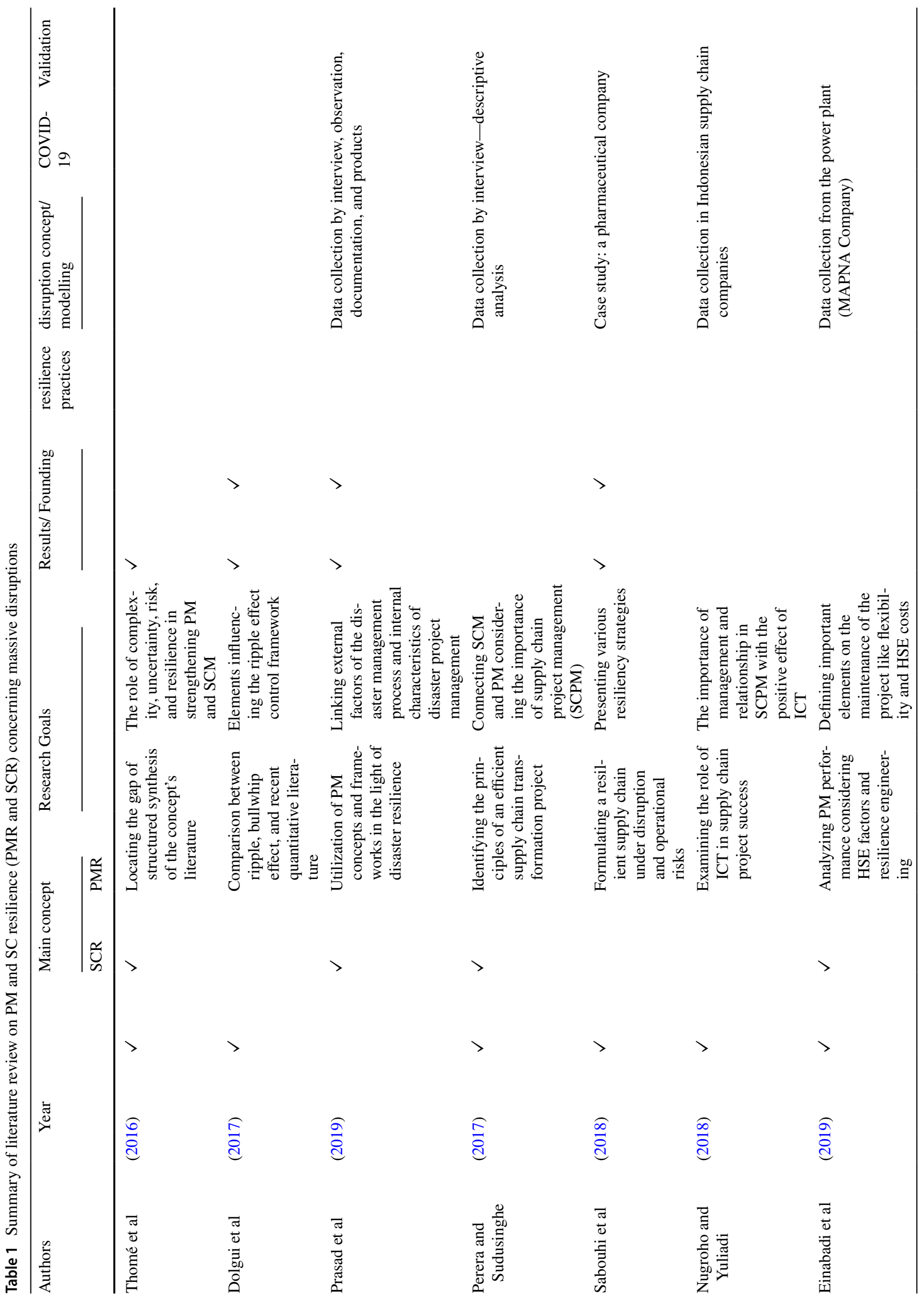




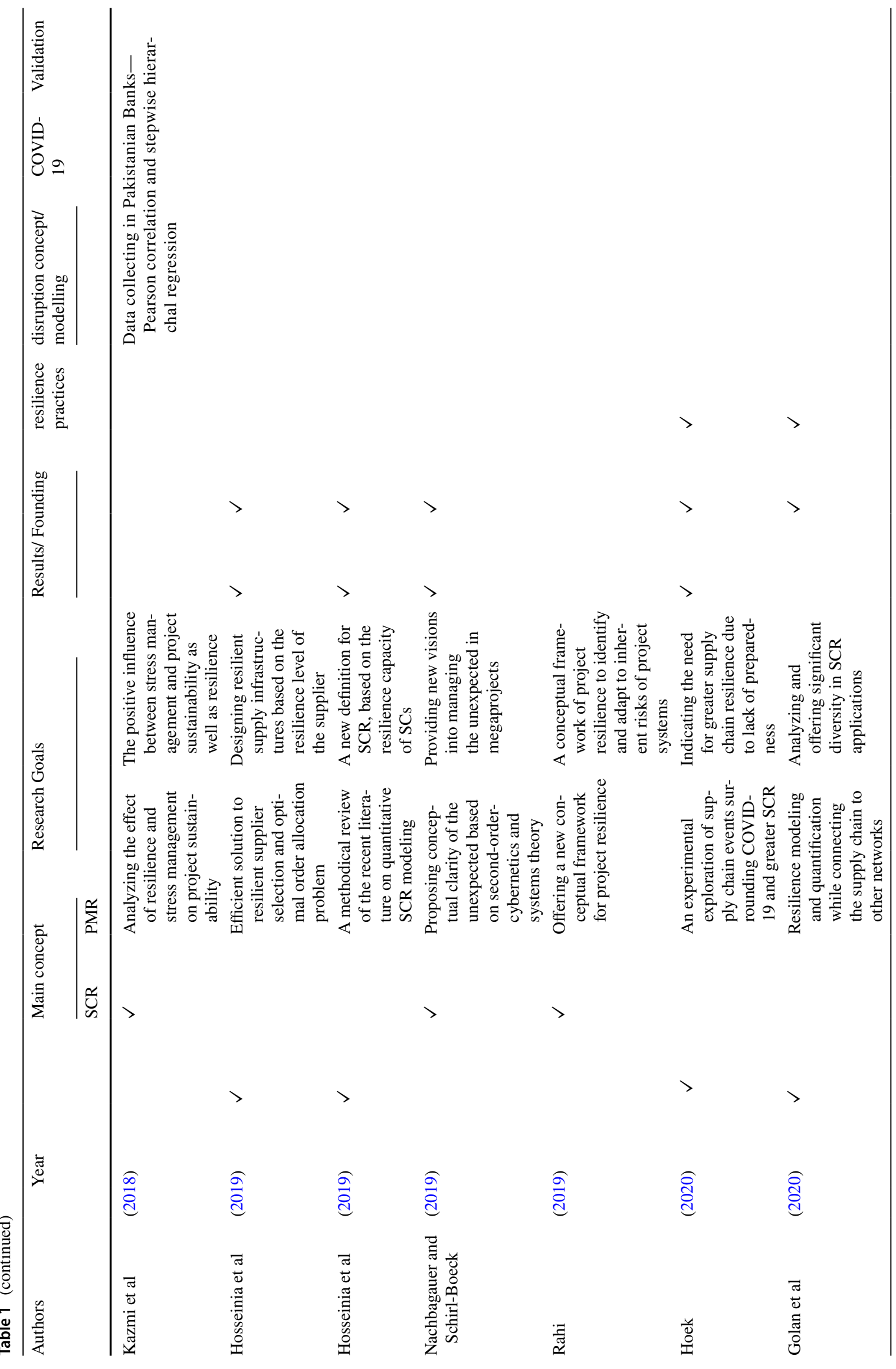




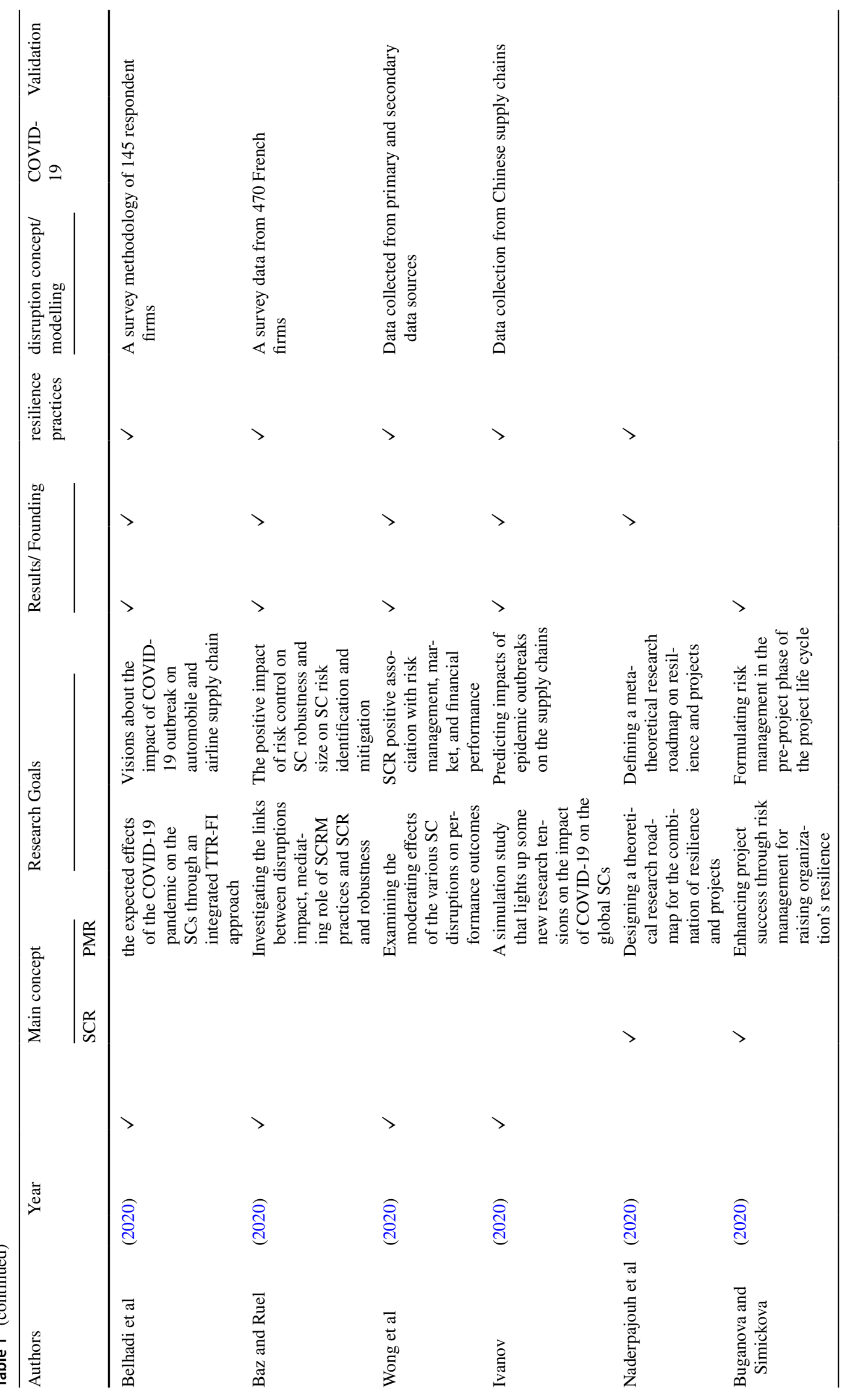


A scenario-based robust time-cost tradeoff model to handle the effect of COVID-19 on supply chains...

365

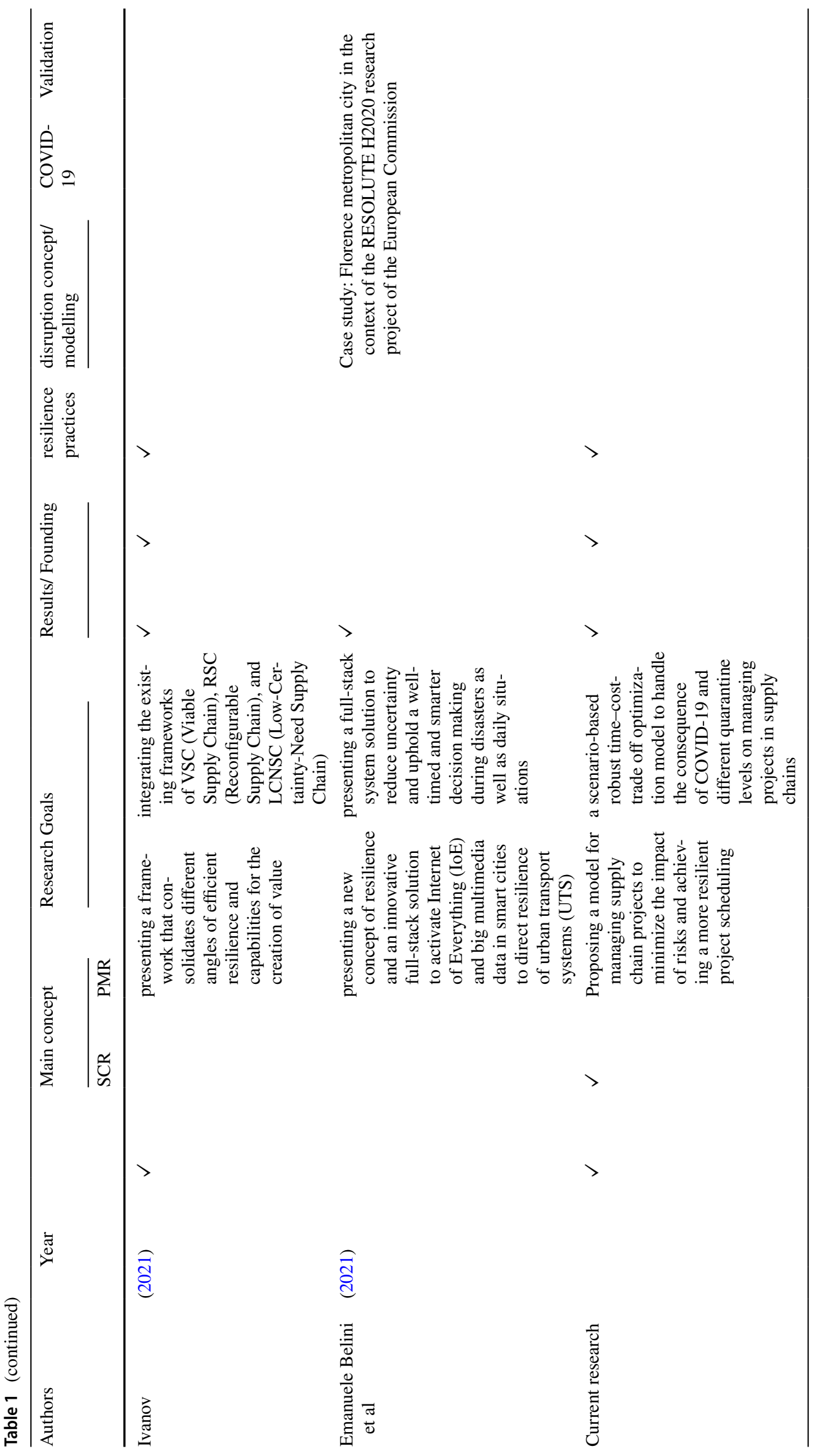

Springer 
Table 2 A summary of TCTP models and their extensions

\begin{tabular}{|c|c|c|c|c|c|c|c|c|}
\hline \multirow[t]{2}{*}{ Researcher } & \multirow[b]{2}{*}{ Year } & \multicolumn{4}{|c|}{ Dimensions } & \multirow[t]{2}{*}{ Type } & \multirow[t]{2}{*}{ Uncertainty } & \multirow[t]{2}{*}{ Algorithm } \\
\hline & & Time & Cost & Risk & Other & & & \\
\hline Kang and Choi & $(2015)$ & $\checkmark$ & $\checkmark$ & & & Discrete & Stochastic & Dynamic programming \\
\hline Lee et al & $(2015)$ & $\checkmark$ & $\checkmark$ & & & Discrete & Stochastic & $\begin{array}{l}\text { CPM-Guided genetic } \\
\text { algorithm }\end{array}$ \\
\hline Tran et al & $(2015)$ & $\checkmark$ & $\checkmark$ & & Quality & Discrete & - & $\begin{array}{l}\text { hybridization of an artifi- } \\
\text { cial bee colony and } \\
\text { differential evolution }\end{array}$ \\
\hline Choi and Park & $(2015)$ & $\checkmark$ & $\checkmark$ & & & Continuous & & $\begin{array}{l}\text { Pseudo-polynomial time } \\
\text { algorithm }\end{array}$ \\
\hline Hazir et al & $(2015)$ & $\checkmark$ & $\checkmark$ & & & Discrete & Robust & Robust optimization \\
\hline Tran et al & $(2015)$ & $\checkmark$ & $\checkmark$ & & Labor utilization & & & $\begin{array}{l}\text { Multiple Objective } \\
\text { Symbiotic Organisms } \\
\text { Search }\end{array}$ \\
\hline Shahriari & (2016) & $\checkmark$ & $\checkmark$ & & & Discrete & - & NSGA-II \\
\hline Hochbaum & (2016) & $\checkmark$ & $\checkmark$ & & & Continuous & - & PD-Algorithm \\
\hline $\begin{array}{l}\text { Aminbakhsh and } \\
\text { Sonmez }\end{array}$ & (2016) & $\checkmark$ & $\checkmark$ & & & Discrete & - & $\begin{array}{l}\text { Discrete particle swarm } \\
\text { optimization }\end{array}$ \\
\hline $\begin{array}{l}\text { Göçken and } \\
\text { Baykasoğlu }\end{array}$ & (2016) & $\checkmark$ & $\checkmark$ & & & Continuous & Fuzzy & $\begin{array}{l}\text { Fuzzy ranking method } \\
\text { and the tabu search } \\
\text { (TS) algorithm }\end{array}$ \\
\hline Wood & (2017) & $\checkmark$ & $\checkmark$ & & Quality & Continuous & Stochastic & $\begin{array}{l}\text { Fuzzy memetic optimi- } \\
\text { zation }\end{array}$ \\
\hline Bettemir and Birgonul & (2017) & $\checkmark$ & $\checkmark$ & & & Continuous & - & $\begin{array}{l}\text { Network analysis algo- } \\
\text { rithm }\end{array}$ \\
\hline Tran et al & (2018) & $\checkmark$ & $\checkmark$ & $\checkmark$ & & Continuous & - & $\begin{array}{l}\text { Adaptive multiple } \\
\text { objective differential } \\
\text { evolution }\end{array}$ \\
\hline Tran et al & (2019) & $\checkmark$ & $\checkmark$ & & & Continuous & Stochastic & $\begin{array}{l}\text { Adaptive multiple objec- } \\
\text { tive symbiotic organ- } \\
\text { isms search }\end{array}$ \\
\hline Haghighat et al & (2019) & $\checkmark$ & $\checkmark$ & $\checkmark$ & Quality & Continuous & Interval-valued fuzzy & $\begin{array}{l}\text { Linear binary program- } \\
\text { ming }\end{array}$ \\
\hline $\begin{array}{c}\text { Ballesteros-Perez, } \\
\text { Elmarousy, and } \\
\text { Gonzalez-Cruz }\end{array}$ & (2019) & $\checkmark$ & $\checkmark$ & & & Continuous & Stochastic & Genetic algorithm \\
\hline $\begin{array}{l}\text { Banihashemi and } \\
\text { Khalilzadeh }\end{array}$ & $(2020)$ & $\checkmark$ & $\checkmark$ & & $\begin{array}{l}\text { Quality and environmen- } \\
\text { tal impact }\end{array}$ & Discrete & - & $\begin{array}{l}\text { Data envelopment } \\
\text { analysis }\end{array}$ \\
\hline Jeunet and Orm & $(2020)$ & $\checkmark$ & $\checkmark$ & & Quality & Continuous & - & Lexicographic approach \\
\hline $\begin{array}{l}\text { Godinho and Paulo } \\
\text { Costa }\end{array}$ & $(2020)$ & $\checkmark$ & $\checkmark$ & & & Continuous & Stochastic & Dynamic programming \\
\hline Askarifard et al & $(2021)$ & & $\checkmark$ & $\checkmark$ & $\begin{array}{l}\text { Socio-environmental } \\
\text { impact }\end{array}$ & Continuous & Robust & Epsilon-constraint \\
\hline Banihashemi et al & $(2021)$ & $\checkmark$ & $\checkmark$ & & $\begin{array}{l}\text { Quality and environmen- } \\
\text { tal impact }\end{array}$ & Discrete & - & Epsilon-constraint \\
\hline Hamta et al & $(2021)$ & $\checkmark$ & $\checkmark$ & & Quality & Continuous & - & Goal programming \\
\hline Current research & & $\checkmark$ & $\checkmark$ & $\checkmark$ & & Discrete & Robust & $\begin{array}{l}\text { Scenario-based robust } \\
\text { optimization }\end{array}$ \\
\hline
\end{tabular}

formulated in this section. In the current study, the operational research approach is used to examine the problem. This approach includes four stages of (1) conceptualization, (2) modeling (sub-Sects. 3.1 and 3.2), (3) model solving (sub-Sect. 3.3) and (4) implementation (Sect. 4) (Bertrand and Fransoo 2002). In the conceptualization stage, considering an activity-on-node (AON) representation, a project can be defined as a directed acyclic graph $G=(V, E)$ where the node-set $V$ illustrates project activities and the arc set $E$ illustrates instant transformation between activities (Yang 
and Wang 2010). First, the notation used in modeling the problem is introduced in the following section.

\subsection{Notation and model formulation}

\subsubsection{Parameters}

$i$ index of project activities $i=1,2, \ldots, n$

$M(i)$ Number of execution modes for activity $i$,

$\Gamma(i)$ Set of precedence activities of $i$,

$t_{i k}$ Time of performing activity $i$ in mode $k$ (days);

$c_{i k}$ Cost of performing activity $i$ in mode $k(\$)$;

$r_{i k}$ Risk of performing activity $i$ in mode $k$;

\subsubsection{Variables}

$s_{i}$ start time of activity $i$;

$x_{i k}=\left\{\begin{array}{c}\text { 1ifactivityiisperformedinmodek } \\ \text { 0otherwise }\end{array}\right.$

\subsection{TCRT model}

According to the notation, each activity $i \in V$ has a finite number of execution modes $M(i)$. For each mode $k \in M(i)$, the activity requires a time $t_{i k}$, a cost $c_{i k}$, and a risk $r_{i k}$. The formulated model aims to determine the optimal mode of execution for project activities such that total project time, cost, and risk become simultaneously as optimal as possible, Therefore, the multi-objective mixed-integer TCRT problem is formulated as follows.

Equations 1, 2 and 3 are the objective functions of the model. The first objective, Eq. (1), minimizes the total time of performing a project's activities. The second objective, Eq. (2), minimizes the total cost of activities and the third objective minimizes the total risks of activities. All of these functions are defined as the sum of the selected execution mode of activities time, cost, and quality.

$$
\begin{aligned}
& \text { MinT }=\sum_{i=1}^{n} \sum_{k=1}^{M(i)} t_{i k} x_{i k} \\
& \text { MinC }=\sum_{i=1}^{n} \sum_{k=1}^{M(i)} c_{i k} x_{i k} \\
& \text { MinR }=\sum_{i=1}^{n} \sum_{k=1}^{M(i)} r_{i k} x_{i k}
\end{aligned}
$$

S.T
$M$

(i)

$\sum_{k=1} x_{i k}=1, \forall i, i=1,2, \ldots, M(i)$

$$
\begin{gathered}
s_{i}-s_{j}-\sum_{k=1}^{M(j)} t_{i k} x_{i k} \geq 0, \forall j, j \in \Gamma(i) \\
s_{i} \geq 0, i=1,2, \ldots, n \\
x_{i k}=\{0,1\}, i=1,2, \ldots, n ; k=1,2, \ldots, M(i)
\end{gathered}
$$

The first constraint, i.e. Equation (4), requires that each activity can be executed in one of its available execution modes since it is not possible to consider more than one execution mode for each activity. The second constraint, i.e. Equation (5), illustrates the precedence relations among activities. The constraint assured that the time difference between starting time of two consequent activities must be greater than the execution time required for performing the precedent activity. It might possible to add another constraint that required the project to be completed in a predetermined time $T$. this constraint can be illustrated as follows.

$s_{n} \leq T$

\subsection{A robust counterpart of the TCRT problem}

The model formulated in Eqs. (1, 2, 3, 4 and 5) is a deterministic multi-objective mixed-integer programming model considering all of the parameters are determined exactly. In the pandemic situation; however, it is almost impossible to perform activities without any deviation in their parameters. To achieve a more resilient supply chain project management, a robust formulation of the TCTR problem is developed in this section. The Covid-19 pandemic affects the TCRT problem based on stages of quarantine. These quarantine stages affect the activities' time, cost, and risk. These stages are determined as isolation $\left(\mathrm{Q}_{1}\right)$, quarantine $\left(\mathrm{Q}_{2}\right)$, social distancing $\left(\mathrm{Q}_{3}\right)$, and lock-down $\left(\mathrm{Q}_{4}\right)$. These stages of quarantine can be considered as different scenarios affecting the completion of the project. Therefore, a scenario-based robust counterpart of the TCRT problem is formulated. Suppose that the problem is formulated as below (Mulvey et al. 1995)

$\operatorname{Minc}^{T} x+d^{T} y$

$A x=b$

$B x+C y=e$

$x, y \geq 0, x \in R^{n_{1}}, y \in R^{n_{2}}$

where Eq. (8) is a structural constraint with fixed coefficients and Eq. (9) is a control constraint with noisy coefficients. A 
set of scenarios $\Omega=\{1,2, \ldots, S\}$ are introduced and under each scenario $s \in \Omega$, a set $\left\{d_{s}, B_{s}, C_{s}, e_{s}\right\}$ of coefficients are realized. Furthermore, the probability of scenario $s$ is $p_{s}$, where $\sum_{s=1}^{S} p_{s}=1$. Mulvey et al. (1995) introduced the concepts of solution robustness and model robustness about the closeness of optimal solution and remains almost feasible for the different realization of model parameters, respectively. Under these circumstances, the robust counterpart is formulated as follows.

$\operatorname{Min} \sigma\left(x, y_{1}, \ldots, y_{S}\right)+w \rho\left(z_{1}, \ldots, y_{S}\right)$

\section{S.T}

$A x=b$

$B_{s} x+C_{s} y_{s}+z_{s}=e_{s} \forall s \in \Omega$

$x \geq 0, y_{s} \geq 0, \forall s \in \Omega$

where $\left\{y_{1}, y_{2}, \ldots, y_{s}\right\}$ are the set of control variables for each scenario $s \in \Omega$, and $\left\{z_{1}, z_{2}, \ldots, z_{s}\right\}$ are the set of error variables to measure the allowed infeasibility of control constraints under the $s^{\text {th }}$ scenario. In the above model, $\sigma$ and $\rho$ terms are defined as the solution robustness and model robustness function assuring the optimality and feasibility of the solution against different scenarios. The first term in Eq. (11) assured the solution robustness of the problem. Using the idea of mean-variance, this term can be formulated as follows.

$\sigma\left(x, y_{1}, \ldots, y_{S}\right)=\sum_{s \in S} p_{s} \xi_{s}+\lambda \sum_{s \in S} p_{s}\left(\xi_{s}-\sum_{s \in S} p_{s} \xi_{s}\right)^{2}$

where $\lambda$ is the assigned weight to the variability of the solutions and $\xi_{s}$ is the realized value of an objective function under the $s^{\text {th }}$ scenario. The quadratic term of Eq. (15) can be replaced by

$\sigma\left(x, y_{1}, \ldots, y_{S}\right)=\sum_{s \in S} p_{s} \xi_{s}+\lambda \sum_{s \in S} p_{s}\left|\xi_{s}-\sum_{s \in S} p_{s} \xi_{s}\right|$

Using non-negative deviation variables $\theta_{s}^{-}$and $\theta_{s}^{+}$, the model in Eq. (16) is transformed into the following linear model.

Min $=\sum_{s \in S} p_{s} \xi_{s}+\lambda \sum_{s \in S} p_{s}\left(\theta_{s}^{-}+\theta_{s}^{+}\right)$

S.T

$\xi_{s}-\sum_{s \in S} p_{s} \xi_{s}-\theta_{s}^{-}+\theta_{s}^{+}=0 \forall s \in \Omega$ $\theta_{s}^{-}, \theta_{s}^{+} \geq 0$

The second term of Eq. (11) is a function to assure the model robustness by penalizing the infeasibilities. This term compensates for the infeasibilities due to some scenarios, illustrated as $\delta_{s}$. The weight $w$ made a balance between solution and model robustness. A greater value of $w$ reduces the possible infeasibility. The final robust counterpart is formulated as below.

Min $=\sum_{s \in S} p_{s} \xi_{s}+\lambda \sum_{s \in S} p_{s}\left(\theta_{s}^{-}+\theta_{s}^{+}\right)+w \sum_{s \in S} p_{s} \delta_{s}$

S.T

$A x=b$

$B_{s} x+C_{s} y_{s}+\delta_{s}=e_{s} \forall s \in \Omega$

$\xi_{s}-\sum_{s \in S} p_{s} \xi_{s}-\theta_{s}^{-}+\theta_{s}^{+}=0 \forall s \in \Omega$

In the TCRT problem, the parameters $t_{i k}, c_{i k}$, and $r_{i k}$ depend on the quarantine scenario being executed. Therefore, there is a set of scenarios $\Omega=\{1,2,3,4\}$ corresponding to $\mathrm{Q}_{1}, \mathrm{Q}_{2}, \mathrm{Q}_{3}, \mathrm{Q}_{4}$ with an approximated probability vector $\left\{p_{1}, p_{2}, p_{3}, p_{4}\right\}$, where $\sum_{s=1}^{4} p_{s}=1$. For each scenario, the activity time, cost, and risk parameters acquired different realizations illustrated by $\left\{t_{i k}^{s}, c_{i k}^{s}, r_{i k}^{s}\right\}, s \in\{1,2,3,4\}$. Therefore, the multi-objective robust counterpart of the TCRT problem is formulated as below.

$\operatorname{MinT}=\sum_{s=1}^{4} p_{s}\left(\sum_{i=1}^{n} \sum_{k=1}^{M(i)} t_{i k}^{s} x_{i k}\right)+\sum_{s=1}^{4} p_{s}\left(\theta_{1 s}^{-}+\theta_{1 s}^{+}\right)+\sum_{s=1}^{4} p_{s} \delta_{s}^{-}$

$\operatorname{Min} C=\sum_{s=1}^{4} p_{s}\left(\sum_{i=1}^{n} \sum_{k=1}^{M(i)} c_{i k}^{s} x_{i k}\right)+\sum_{s=1}^{4} p_{s}\left(\theta_{2 s}^{-}+\theta_{2 s}^{+}\right)$

$\operatorname{MinR}=\sum_{s=1}^{4} p_{s}\left(\sum_{i=1}^{n} \sum_{k=1}^{M(i)} r_{i k}^{s} x_{i k}\right)+\sum_{s=1}^{4} p_{s}\left(\theta_{3 s}^{-}+\theta_{3 s}^{+}\right)$

S.T

$\sum_{k=1}^{M(i)} x_{i k}=1, \forall i, i=1,2, \ldots, M(i)$

$s_{i}-s_{j}-\sum_{k=1}^{M(j)} t_{i k}^{s} x_{i k}+\delta_{s}^{-}-\delta_{s}^{+}=0, \forall j, j \in \Gamma(i) ; \forall s, s \in\{1,2,3,4\}$ 


$$
\begin{aligned}
& \left(\sum_{i=1}^{n} \sum_{k=1}^{M(i)} t_{i k}^{s} x_{i k}\right)-\sum_{s=1}^{4} p_{s}\left(\sum_{i=1}^{n} \sum_{k=1}^{M(i)} t_{i k}^{s} x_{i k}\right)-\theta_{1 s}^{-}+\theta_{1 s}^{+}=0, \forall s, s \in\{1,2,3,4\} \\
& \left(\sum_{i=1}^{n} \sum_{k=1}^{M(i)} c_{i k}^{s} x_{i k}\right)-\sum_{s=1}^{4} p_{s}\left(\sum_{i=1}^{n} \sum_{k=1}^{M(i)} c_{i k}^{s} x_{i k}\right)-\theta_{2 s}^{-}+\theta_{2 s}^{+}=0, \forall s, s \in\{1,2,3,4\} \\
& \left(\sum_{i=1}^{n} \sum_{k=1}^{M(i)} r_{i k}^{s} x_{i k}\right)-\sum_{s=1}^{4} p_{s}\left(\sum_{i=1}^{n} \sum_{k=1}^{M(i)} r_{i k}^{s} x_{i k}\right)-\theta_{3 s}^{-}+\theta_{3 s}^{+}=0, \forall s, s \in\{1,2,3,4\}
\end{aligned}
$$

$$
\begin{gathered}
\theta_{1 s}^{-}, \theta_{1 s}^{+}, \theta_{2 s}^{-}, \theta_{2 s}^{+}, \theta_{3 s}^{-}, \theta_{3 s}^{+} \in\{1,2,3,4\} \\
\delta_{s}^{-}, \delta_{s}^{+} \geq 0, s \in\{1,2,3,4\} \\
s_{i} \geq 0, i=1,2, \ldots, \mathrm{n} \\
x_{i k}=\{0,1\}, i=1,2, \ldots, n ; k=1,2, \ldots, M(i)
\end{gathered}
$$

To solve the multi-objective model, an Lp-metric-based approach is used in this study. To this aim, initially, three single objective problems were solved to determine the optimal values of the three objective functions. Suppose that these optimal objectives, i.e., ideal values, are demonstrated by $T^{*}, C^{*}$, and $R^{*}$. Finally, the following single-objective model was solved to determine the robust optimal solution of the TCRT problem as follows.

$\operatorname{Minw}_{T} \cdot \frac{T-T^{*}}{T^{*}}+w_{C} \cdot \frac{C-C^{*}}{C^{*}}+w_{R} \cdot \frac{R-R^{*}}{R^{*}}$

\section{S.T}

$$
\begin{aligned}
& \sum_{k=1}^{M(i)} x_{i k}=1, \forall i, i=1,2, \ldots, M(i) \\
& s_{i}-s_{j}-\sum_{k=1}^{M(j)} t_{i k}^{s} x_{i k}+\delta_{i j s}^{-}-\delta_{i j s}^{+}=0, \forall j, j \in \Gamma(i) ; \forall s, s \in\{1,2,3,4\}
\end{aligned}
$$

$$
\begin{aligned}
& \left(\sum_{i=1}^{n} \sum_{k=1}^{M(i)} t_{i k}^{s} x_{i k}\right)-\sum_{s=1}^{4} p_{s}\left(\sum_{i=1}^{n} \sum_{k=1}^{M(i)} t_{i k}^{s} x_{i k}\right)-\theta_{1 s}^{-}+\theta_{1 s}^{+}=0, \forall s, s \in\{1,2,3,4\} \\
& \left(\sum_{i=1}^{n} \sum_{k=1}^{M(i)} c_{i k}^{s} x_{i k}\right)-\sum_{s=1}^{4} p_{s}\left(\sum_{i=1}^{n} \sum_{k=1}^{M(i)} c_{i k}^{s} x_{i k}\right)-\theta_{2 s}^{-}+\theta_{2 s}^{+}=0, \forall s, s \in\{1,2,3,4\} \\
& \left(\sum_{i=1}^{n} \sum_{k=1}^{M(i)} r_{i k}^{s} x_{i k}\right)-\sum_{s=1}^{4} p_{s}\left(\sum_{i=1}^{n} \sum_{k=1}^{M(i)} r_{i k}^{s} x_{i k}\right)-\theta_{3 s}^{-}+\theta_{3 s}^{+}=0, \forall s, s \in\{1,2,3,4\}
\end{aligned}
$$




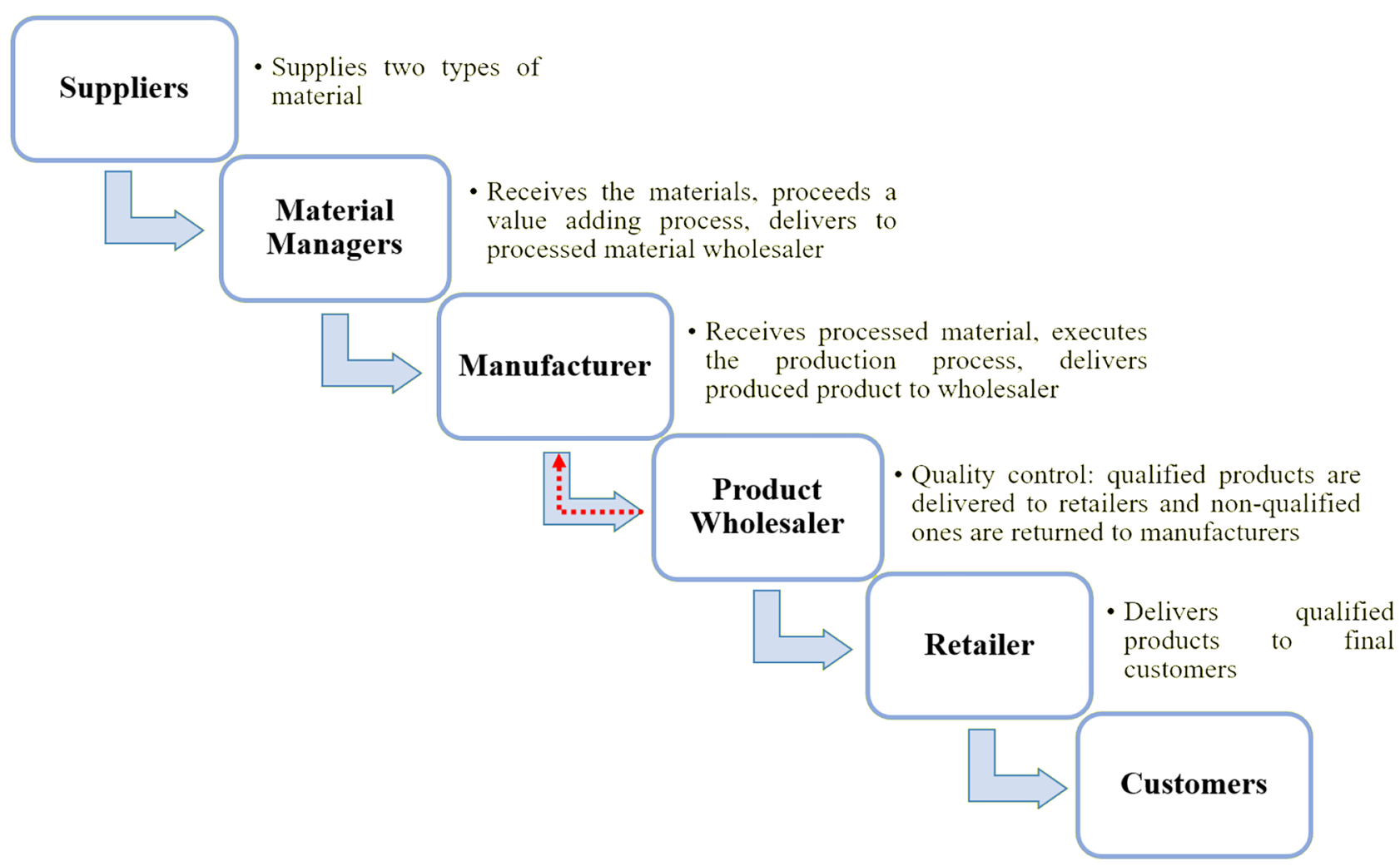

Fig. 1 Studied supply chain

the company decided to take action towards making the supply chain more resistant. Since different levels of disruption have forced the supply chain to go through special changes and coordination; consequently, the company has transferred its supply chain management to a customized online platform to preserve the flow of activities while accelerating the new-designed processes. For instance, the work controlling patterns have changed and new middle management levels have been added to the network.

Based on Fig. 1, the company has a chain of activities that are connected and are tied in each level of the supply chain. Multiple suppliers provide two types of material including tangible (buildings, scene facilities, etc.) or intangible (services like set decorating, directing, acting, etc.). These materials are received by the material manager of the SC to send to different manufacturers who produce variant types of contents or holding different kinds of events. In the next stage, the contents are transformed to some kind of wholesaler who provides two kinds of services. The wholesaler conducts quality control over outcomes and if the quality meets predetermined specifications, they are ready to be served to final consumers or the company who ordered them; otherwise, they will be sent back to the manufacturing process.

In these circumstances when supply chains face disruptions, it is impossible to proceed while a part or a member of the chain is weakened. Thus, when all over the globe is dealing with COVID-19 effects and companies are seeking for solutions to soothe the effects, many firms decide to work online and remotely. The studied company in this article has chosen the same path to survive. To make the remote work efficient, the company decided to use an online project management platform. However, transferring the whole SC to the new platform requires some prerequisites and activities during the successful transformation process. The activities and their connections have been mentioned and explained as an activity-on-node (AON) network as illustrated in Fig. 2.

The considered transformation project consists of 14 activities as follows.

1. Separating the virtual work environment from the real one. In order to be clear and building a whole different and proper space for online working, these two environments should be separated.

2. Identifying the difference between the virtual and real environment. Every environment has its policies and for preparing the staff for new space, identifying the rules and differences is an essential issue.

3. Redefining the workflow. If a project changes the whole workflow, redefining it for blocking any probable problem is required. 


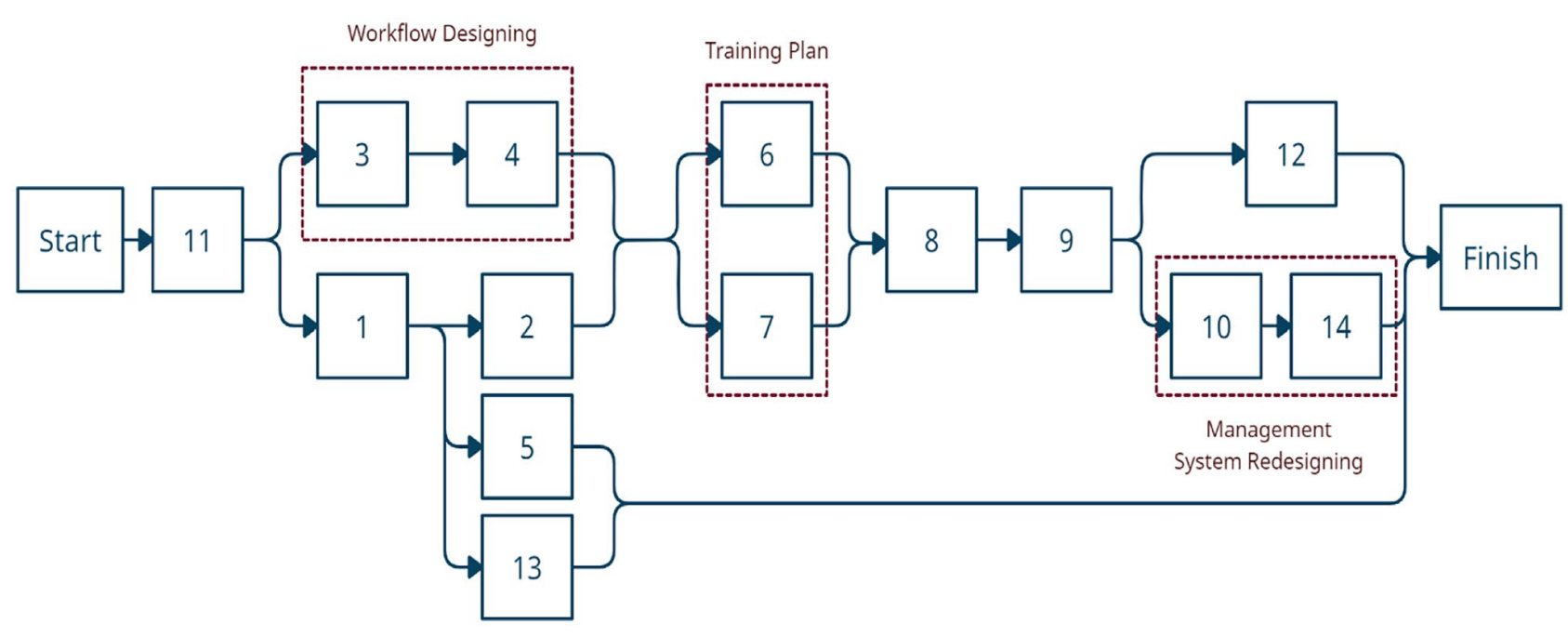

Fig. 2 The Transformation project activity network

4. Reengineering the workflow. After defining a new workflow, debugging the new process is required.

5. Boosting the development team to integrate with the platform.

6. Training the human resources on the new platform. Human resources are our key users so they have to get fully briefed about the new project management platform.

7. Training the human resource on the new workflow.

8. Preparing the software and hardware equipment. Technology should stay updated while companies are working online.

9. Defining new monitoring plans.

10. Adding new middle management levels to the hierarchy. When a supply chain grows, new management plans should be generated.

11. Collecting objective data instead of a subjective one. Data can be tracked and recorded more practically.

12. Decentralizing the management system.

13. Boosting family culture. To not losing staff's loyalty, because of missing physical communication this action is crucial.

14. Hiring senior human resources.

These activities based on their nature can implement internally or be outsourced to a contractor. Consequently, there are variant scenarios to be examined for some activities. The time, cost, and risk of each activity are different in 4 levels of Quarantine (isolation, quarantine, social distancing, and lock-down). Table 3 illustrates this information for different activities under different scenarios.

As we can see, in some activities, after experiencing pandemic, costs have been reduced. The main reasons are remote working and using online platforms instead of traditional procedures. The considered project is examined in the next subsection.

\section{Results and discussion}

Considering the described problem, the robust TCRT model is formulated and solved using LINGO software. The obtained results are discussed in this subsection. First of all, if any one of the quarantine levels has occurred, the formulated problem can be solved by setting $p_{i}=1, i \in\left\{Q_{1}, Q_{2}, Q_{3}, Q_{4}\right\}$. The values of time, cost, and risk objectives in these extreme cases are illustrated in Table 4.

As it can be expected, increasing the level of quarantine might increase the required time for project completion and its associated cost and risk. Based on Table $4, T^{*}=36, C^{*}=260000$, and $R^{*}=141$. Then, the multi-objective problem, i.e., Eqs. (29-35), is solved considering four different statutes of ruling out a single scenario, i.e. $p_{i}=1, i \in\left\{Q_{1}, Q_{2}, Q_{3}, Q_{4}\right\}$ and $p_{k}=0, k \in\left\{Q_{1}, Q_{2}, Q_{3}, Q_{4}\right\}, k \neq i$, and also when different scenarios have equal probabilities, i.e. $p_{i}=0.25, i \in\left\{Q_{1}, Q_{2}, Q_{3}, Q_{4}\right\}$. Table 5 illustrates the obtained results.

To achieve a better understanding of the impact of changing quarantine level probabilities on the results, the following scenario is examined. For a given quarantine scenario, a given probability $p_{i}=0,0.1,0.2, \ldots, 1$ is fixed and the probabilities of the remaining scenarios are specified as $p_{i^{\prime}}=\left(1-p_{i}\right) / 3, i^{\prime} \in\{1,2,3,4\}, i \neq i^{\prime}$. Figure 3a-d, drawn by MATLAB R 2016b, represents the effect of changing different scenario probabilities with the same remaining scenario probabilities on time, cost, and risk objectives. 
Table 3 Time, cost, and risk of project activities under different scenarios at different levels of pandemic

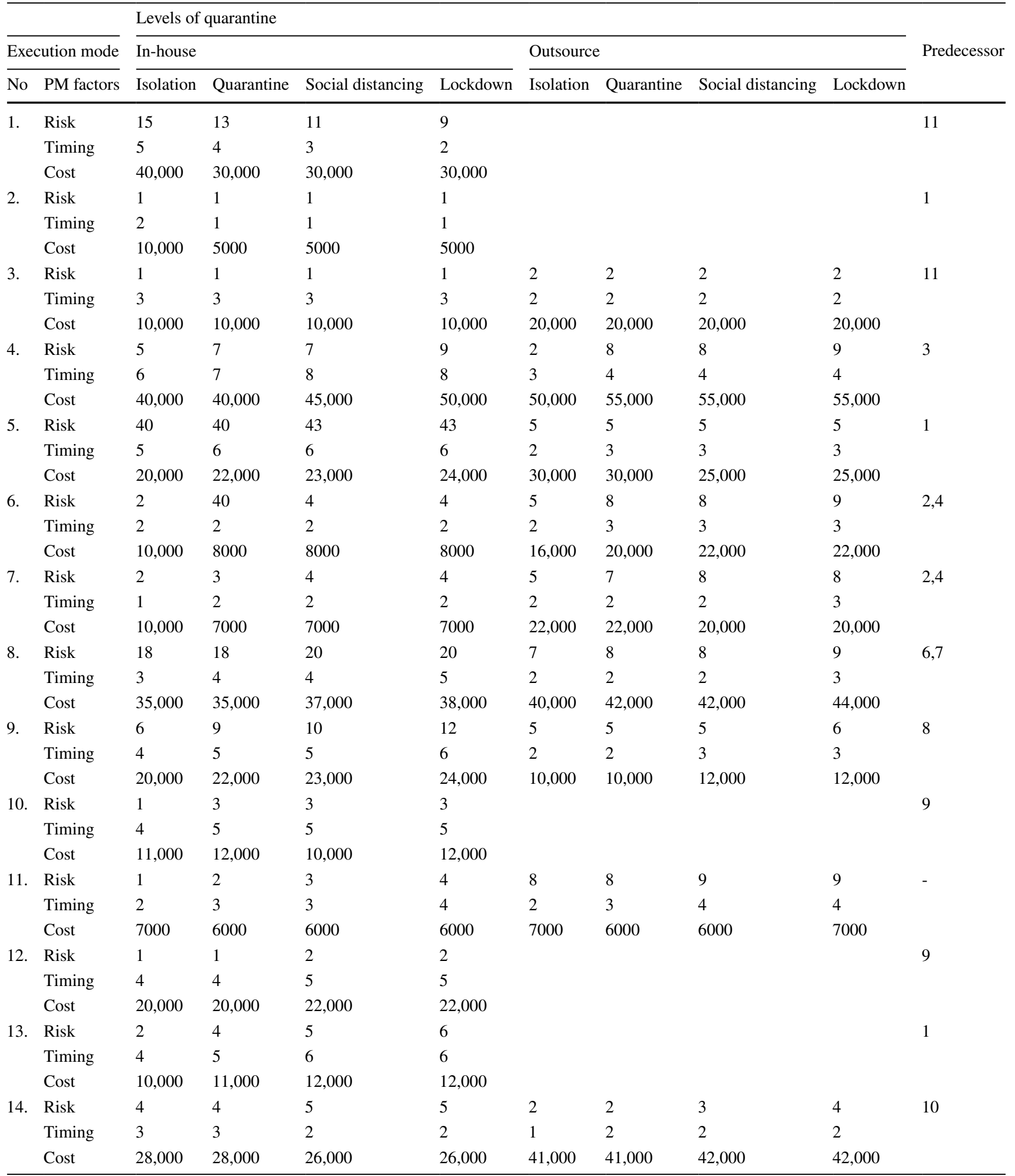

According to the above figure, it can be concluded that decreasing the probability of both isolation and quarantine, i.e. $1^{\text {st }}$ and $2^{\text {nd }}$ scenarios respectively, will increase the time of the project. The most influential scenario on project time is quarantine $\left(\mathrm{Q}_{2}\right)$ where the time objective increase from 43 to about 70 by decreasing quarantine probability from 
Table 4 The optimal time, cost, and quality objectives in extreme cases

\begin{tabular}{lllll}
\hline & Isolation & Quarantine & Social distancing & Lock-down \\
\hline Time & 36 & 41 & 43 & 44 \\
Cost & 260,000 & 732,000 & 759,000 & 786,000 \\
Risk & 141 & 162 & 186 & 201 \\
\hline
\end{tabular}

1 to 0 . On the other hand, when the first scenario (isolation) becomes impossible, $p_{1}=0$, the project risk is worsening about 40 percent; while the riskiest scenario is when the lock-down is happening. The less sensitive objective to scenario probabilities seems to be the cost objective. Furthermore, considering Fig. 3a-d, the following points were extracted.

- According to Fig. 3a, by decreasing the probability of isolation, the project completion time and cost were increased. However, a partial decrease in project risk was observed while $p_{1} \leq 0.7$. The impact of decreasing isolation probability on the increase of the time and cost of the project is expectable. Certainly, in the first level of quarantine, the resources are available and all the activities are performed in their usual manner. In this scenario, the model prescribed to choose the activities execution mode by balancing their three objectives. For instance, it can be seen that while the isolation scenario becomes dominant, i.e., $p_{1}=1$, the execution mode of activity 4 is determined to be outsourced. While the cost of outsourcing is $25 \%$ higher than the in-house mode, its cost and risk are decreased by about $50 \%$ and $40 \%$, respectively. On the other hand, since decreasing the probability of the lowest level of quarantine means an increase in more strict scenarios, decreasing the probability of isolation negatively affects the project time and cost. Considering the results, the cost and time factors are severely sensitive to isolation probability. Therefore, while the isolation probability is high, the time and cost factors seem to be more important in making decisions regarding the projects. While in lower levels of isolation probability, the risk factor is more important.

- According to Fig. 3b, by decreasing the probability of quarantine, the project completion time increased while two other objectives were mainly decreased. Increasing the probability of quarantine means that a part of the employee will be work remotely. The impact of remote working due to work-home interference, soleness, ineffective communication, etc. (Wang et al. 2021) increases the possibility of an increase in project time and cost. It can be seen that the time dimension is more sensitive to
Table 5 The results of different scenarios (I: in-house; O: outsource)

\begin{tabular}{llllll}
\hline Activity & $\begin{array}{l}\text { Isolation } \\
\left(p_{1}=0\right)\end{array}$ & $\begin{array}{l}\text { Quar- } \\
\text { antine } \\
\left(p_{2}=0\right)\end{array}$ & $\begin{array}{l}\text { Social } \\
\text { distancing } \\
\left(p_{3}=0\right)\end{array}$ & $\begin{array}{l}\text { Lock- } \\
\text { down } \\
\left(p_{4}=0\right)\end{array}$ & $\begin{array}{l}\text { Equal } \\
\text { prob- } \\
\text { abilities }\end{array}$ \\
\hline 1 & I & I & I & I & I \\
2 & I & I & I & I & I \\
3 & I & I & I & I & I \\
4 & O & O & I & O & O \\
5 & O & O & O & O & O \\
6 & I & O & I & I & I \\
7 & I & I & I & I & I \\
8 & O & O & O & O & O \\
9 & O & O & O & O & O \\
10 & I & I & I & I & I \\
11 & I & I & I & I & I \\
12 & I & I & I & I & I \\
13 & I & I & I & I & I \\
14 & O & I & I & I & I \\
\hline
\end{tabular}

quarantine probability. Therefore, at the higher levels of quarantine, the time dimension is important.

- According to Fig. 3c, by decreasing the probability of social distancing, the project completion time increased while the project cost and its risk were decreased.

- According to Fig. 3d, by decreasing the probability of lock-down, the cost, and risk of project completion decreased while the time was increased. The reason for the pattern in this scenario and the previous one is due to the negative effects of remote working and difficulty of communication and the possible disorder in the availability of resources.

The impact of second, third, and fourth scenarios on time dimension can be justified based on the fact that decreasing the probability of more strict quarantine scenarios means that other scenarios might be ruled out in different areas of an area. As an illustration, while some parts of an area are lock-down, other parts might be performed routinely. This mixed scenario can hurt the project time. However, it can be expectable that decreasing the probability of more strict quarantine scenarios can have a positive impact on the project cost and risk. Based on the above discussion, it seems a negative relation between probabilities of different scenarios with project completion time. Decreasing the probability of any scenario, the project completion time was increased due to the increase of other scenarios. However, except for the isolation scenario, i.e. the lowest level of quarantine, decreasing the probability of other scenarios caused higher cost and risk for the project. 


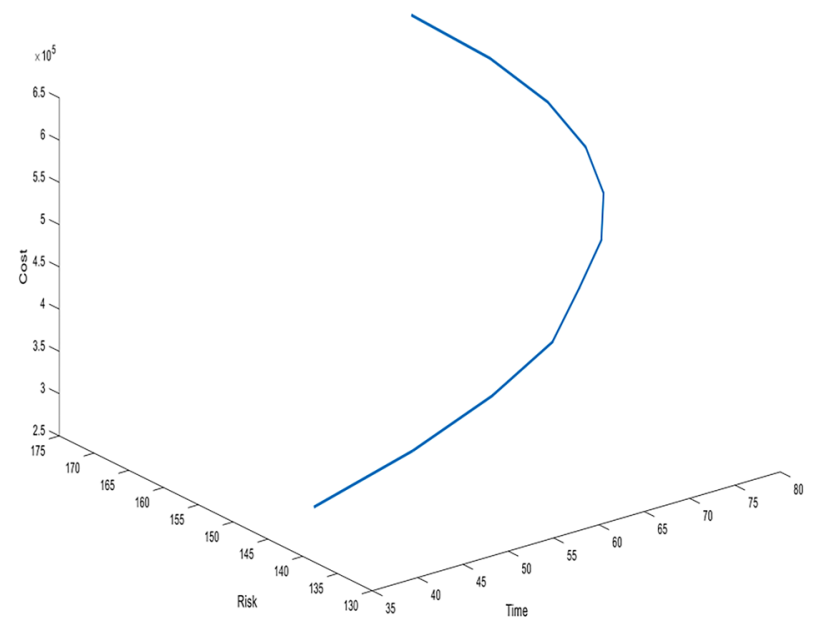

(a) Isolation probability change impact

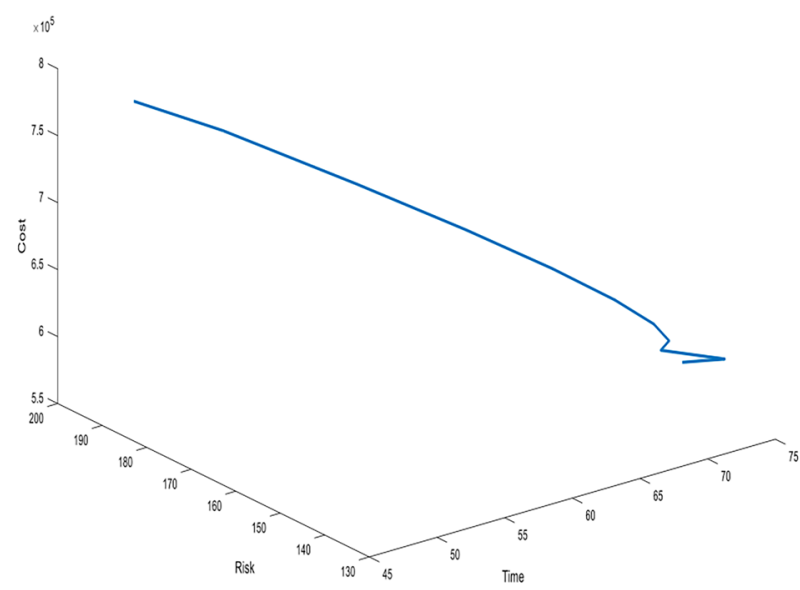

(c) Social distancing probability change impact

Fig. 3 The 3-dimensional Pareto-front for different situations

\section{Conclusions}

The COVID-19 pandemic severely affected supply chains. In the early stages of a pandemic, some of them faced a shortage of goods and unexpected demand for low-consumption goods. On the other hand, the pandemic led to remote working and change the work-places. The Typical configuration of SCM didn't work anymore in this situation. It forced the companies to change the structure of supply chains inevitably. These transformations need to be handled as a project. To be successful, companies need to manage these projects carefully based on the principles of project management. An important issue in managing projects is the time-cost tradeoff problem where the project planner seeks to determine the best combination of activities time and cost to perform the project. Beyond the classic time and cost criteria, in this paper, the risk criterion

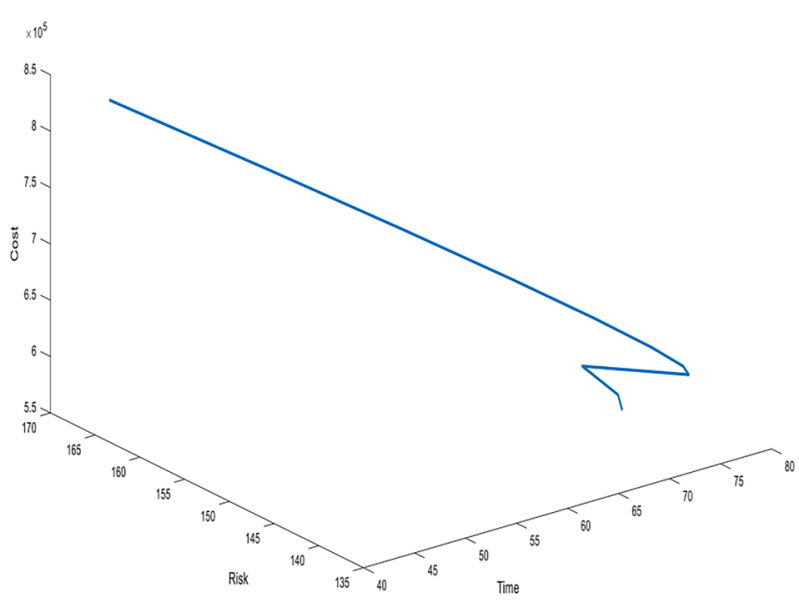

(b) Quarantine probability change impact

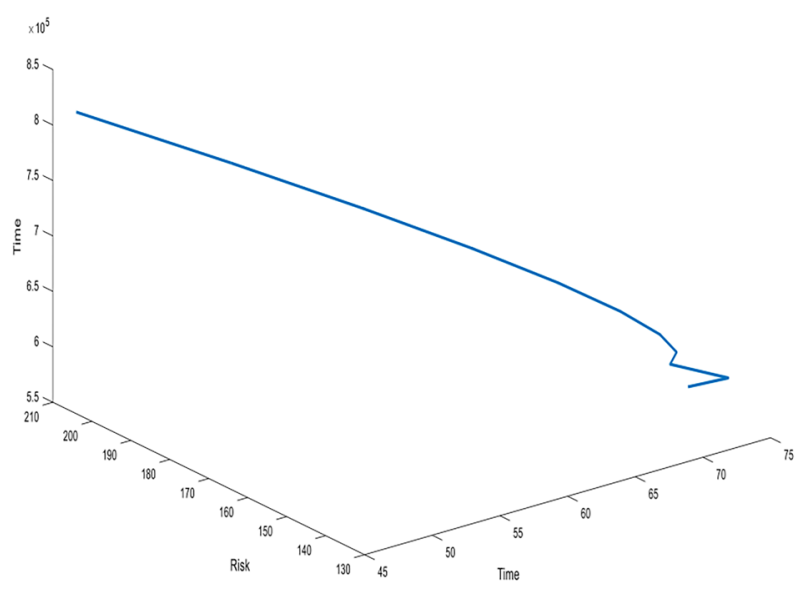

(d) Lock-down probability change impact

is also considered to deal with the uncertainty caused by the COVID-19 outbreak. Theoretically, from the first perspective, according to Table 2, it is clear that previous researches have focused on time, cost, quality, and risk tradeoff problems. Mainly time-cost-tradeoff (TCT) models have been implemented in many applications (e.g. Tran et al. 2019) and uncertain approaches of these tradeoff models have been developed and applied (e.g. Godinho and Paulo Costa 2020). Besides some scholars focused on quality (Jeunet and Orm 2020) and risk (Askarifard et al. 2021) dimensions in their models. To the best knowledge of the authors, previous articles have not developed a scenario-based robust optimization model considering the COVID-19 pandemic. Thus, the main contribution of the current paper is to propose a multi-objective scenario-based robust optimization model to deal with time, cost, and risk tradeoff problems to reflect the effects of the global pandemic 
of COVID-19. Moreover, in this article, various quarantine policies including isolation, quarantine, social distancing, and lock-down have been investigated each as a separate scenario. From the second perspective, as previously discussed in Table 1, many scholars focused on project management resiliency (e.g. Ivanov 2020), and others mainly focused on supply chain resiliency challenges (e.g. Naderpajouh et al. 2020a, b). However, the current article considers both issues including project management and supply chain resiliency issues in the proposed model and approach. The resiliency of supply chain management projects that have affected by a global challenge such as the COVID-19 pandemic has been discussed and investigated in this research through a novel approach.

Practically, supply chain managers can use the proposed method in planning their supply chain projects responding to the pandemic situation for desirable management of projects. The model enables managers to design the best scenario according to the changing situation and to adopt the most suitable decision considering the pandemic expansion. The results of this study can be applied by supply chain, operations, and project managers to enhance the efficiency and effectiveness of processes by turning the resilience approach from passive, costdriving assets into a value-adding and broad decision-making paradigm in times of disruptions. Any increase or decrease in the pandemic outbreak and any changes in quarantine levels can be responded to by managers in guiding their supply chain project to reach an acceptable result with the best conditiondependent time, cost, and risk. As in this article, various quarantine policies including isolation, quarantine, social distancing, and lock-down have been investigated each as a separate scenario, policymakers and managers of national and international logistic and supply chain companies can adopt the same scenario-based approach in the organizations for managing any project. They can prepare and trade-off the time-cost and risk of their project sin SC based on the quarantine level that has been adopted by the authorities. Managers can adjust their decision regarding their project activities execution mode based on their expectancy of future condition occurrence. Tracking the status of the pandemic, managers can change or update their decision based on changing condition of the pandemic outbreak.

The current study considered a multi-mode discrete TCRT problem considering exact and certain values for activity parameters, including execution modes time, cost, and risk. These assumptions constitute the main limitations of the current study. As a clue for future studies, as the current study has adopted discrete analysis, researchers can extend the problem of supply chain management project scheduling problems to continuous modes. Furthermore, since it is assumed that an activity will be performed until completeness after its beginning, the TCRT problem can be extended to the situation with the probability of pausing activities even after their start including start to start (SS), start to finish (SF) and finish to finish (FF) relations between activities. The model can be extended by considering quality dimension as another objective. Furthermore, possible future research can be formulating the considered problem by considering the activity parameters as uncertain values, e.g. when time, cost, and risks of the activities are determined as fuzzy or stochastic values. This change can also be considered by scholars in their future investigations. Theoretically, since all governments implemented different policies to face pandemics, different strategies applied to manage the situation such as various structures of lock-down or social distancing can be considered to extend the designed model in future studies. The resiliency of projects designed to handle the effect of disruptions on SCs can also be investigated in this matter. The project studied in this paper has been devised in the shortest time possible as a quick response to the firm's condition; thus, slight adjustments have been made to obtain more explicitly and measurability. Therefore, the COVID-19 urgent experiences and collected data during this pandemic can be used to build more resilient supply chains and shed light on new resiliency approaches and practices for post-COVID supply chains and projects.

\section{References}

Askarifard M, Abbasianjahromi H, Sepehri M, Zeighami E (2021). A robust multi-objective optimization model for project scheduling considering risk and sustainable development criteria. Envr, Devt and Sustainable 1-31

Aminbakhsh S, Sonmez R (2016) Discrete particle swarm optimization method for the large-scale discrete time-cost trade-off problem. Exp Sys App 51:177-185

Ayers JB (2009) Supply Chain Project Management. CRC Press, Boca Raton, Florida

Ballesteros-Perez P, Elamrousy KM, González-Cruz MC (2019) Nonlinear time-cost trade-off models of activity crashing: Application to construction scheduling and project compression with fast-tracking. Automn in Const 97:229-240

Banihashemi L, Peng CW, Verstynen T, Wallace ML, Lamont DN, Alkhars HM, Yeh FC, Beeney JE, Aizenstein HJ, Germain A (2021) Opposing relationships of childhood threat and deprivation with stria terminalis white matter. Human Brain Mapping 42(8):2445-2460

Banihashemi SA, Khalilzadeh M (2020) Time-cost-quality-environmental impact trade-off resource-constrained project scheduling problem with DEA approach. Eng, Const and Archt Mngmt. ahead-of-print (ahead-of-print)

Baz JE, Ruel S (2021) Can supply chain risk management practices mitigate the disruption impacts on. Int J Prod Econ 233. https:// doi.org/10.1016/j.ijpe.2020.107972

Beheshti M, Amoozad Mahdiraji H, Zavadskas EK (2016). Strategy portfolio optimisation: A COPRAS G-MODM hybrid approach, 15(3C):500-519

Belhadi A, Kamble S, Jabbour CJC, Gunasekaran A, Ndubisi NO, Venkatesh M (2021) Manufacturing and service supply chain resilience to the COVID-19. Technol Forecast Soc Chang 163. https://doi.org/10.1016/j.techfore.2020.120447

Belhadi A, Kamble SS, Khan SA, Touriki FE, Kumar D (2020) Infectious Waste Management Strategy during COVID-19 Pandemic in Africa: an Integrated Decision-Making Framework for Selecting Sustainable Technologies. Environ Mgmnt 66 (6):1085-1104 
Bertrand J, Fransoo J (2002) Operations managementresearch methodologies usingquantitative modeling. Int J Oper Prod Manag 22(2):241-264

Bettemir ÖH, Birgönül MT (2017). Network analysis algorithm for the solution of discrete time-cost trade-off problem. KSCE J Civ Engr 21(4);1047-1058

Buganova K, Simickova J (2020) Increasing the organization's resilience through project risk management. 52nd International Scientific Conference on Economic and Social Development Development, (pp. 163-170). Porto

Choi B-C, Park M-J (2015) A continuous time-cost tradeoff problem with multiple milestones and completely ordered jobs. Euro J Opnl Res 244(3):748-752

Chowdhury MZ, Hossan MT, Shahjalal M, Hasan MK, and Jang YM (2020). A new 5G ehealth architecture based on optical camera communication: an overview, prospects, and applications. IEEE Consum. Electron. Mag 9:23-33.

Chena HY, Das A, Ivanov D (2019) Building resilience and managing post-disruption supply chain recovery: Lessons from the information and communication technology industry. Int J Inf Manage 49:330-342

Crawford L, Langston C, Bajracharya B (2013) Participatory project management for improved disaster resilience. International Journal of Disaster Resilience in the Built Environment 4(3):317-333

de Carvalho M, Rabechini Junior R (2015) Impact of risk management on project performance: the importance of soft skills. Int J Prod Res 53(2):321-340

de Sousa Jabbour AB, Jabbour CJ, Hingley M, Vilalta-Perdomo EL, Ramsden G, Twigg D (2020) Sustainability of supply chains in the wake of the coronavirus (COVID-19/SARS-CoV-2) pandemic: lessons and trends. Modern Supply Chain Res and Apps 2 (3):117-122

Dolgui A, Ivanov D, Sokolov B (2017) Ripple effect in the supply chain: an analysis and recent literature. Inter J Prod Res 56(1-2):414-430

Einabadi B, Baboli A, Ebrahimi M (2019) Dynamic Predictive Maintenance in industry 4.0 based on real time information: Case study in automotive industries.IFAC-PapersOnLine 52(13):1069-1074

Emanuele Bellini PB (2021) An IoE and Big Multimedia Data Approach for Urban Transport System Resilience Management in Smart Cities. (This article belongs to the Special Issue Smart Cities of the Future: A Cyber Physical System Perspective).

Emenike S, Falcone G (2020) A review on energy supply chain resilience through optimization. Renew Sustain Energy Rev 134. https://doi. org/10.1016/j.rser.2020.110088

Frederico G, Garza-Reyes JA, Kumar A (2021) The Role of Project Management for More Resilient Supply Chains: Lessons Learned from COVID-19 Outbreak. Operations Management Research

Garousi Mokhtarzadeh N, Amoozad Mahdiraji H, Jafari-Sadeghi V, Soltani A, Abbasi Kamardi A (2020a) A product-technology portfolio alignment approach for food industry: a multi-criteria decision making with Z-numbers. British Food Journal 122(12):3947-3967

Garousi Mokhtarzadeh N, Amoozad Mahdiraji H, Jafarpanah I, JafariSadeghi V, Cardinali S (2020b) Investigating the impact of networking capability on firm innovation performance: using the resourceaction-performance framework. J Intellect Cap 21(6):1009-1034

Gaudenzi B, Christopher M (2015) Achieving supply chain 'Leagility' through a project management orientation. Int J Log Res Appl 19(1):3-18

Göçken T, Baykasoğlu A (2016) Direct Solution of Time-Cost Tradeoff Problem with Fuzzy Decision Variables. Cybernetics Syst 47(3):206-219

Godinho P, Costa JP (2020) A stochastic model and algorithms for determining efficient time-cost tradeoffs for a project activity. Opnl Res 20(1):319-348

Golan MS, Jernegan LH, Linkov I (2020) Trends and applications of resilience analytics in supply chain modeling: systematic literature review in the context of the COVID-19 pandemic. Environment Systems and Decisions 40(2):222-243

Guttmann A (2021) Retrieved from Statista.com: https://www.statista. com/topics/990/global-advertising-market/\#dossierSummary_chapter5

Haghighat MH, Foroushani ZA, Li J (2019, October). SAWANT: Smart Window Based Anomaly Detection Using Netflow Traffic. In 2019 IEEE 19th Int Conf Commu Tech (ICCT) (pp. 1396-1402). IEEE.

Hajiagha SH, Mahdiraji HA, Hashemi SS (2014) A hybrid model of fuzzy goal programming and grey numbers in continuous project time, cost, and quality tradeoff. The International Journal of Advanced Manufacturing Technology 71(1-4):117-126

Hamta N, Ehsanifar M, Sarikhani J (2021) Presenting a goal programming model in the time-cost-quality trade-off. Inter $\mathrm{J}$ of Cons Mgmnt 21(1):1-11

Hasani A, Khosrojerdi A (2016) Robust global supply chain network design under disruption and uncertainty considering resilience strategies: A parallel memetic algorithm for a real-life case study. Trans Res Part E: Log Trans Rev 87:20-52

Hazır Ö, Haouari M, Erel E (2015). Robust optimization for the discrete time-cost tradeoff problem with cost uncertainty. In Handbook on Project Managementand Scheduling Vol. 2 (pp. 865-874). Springer, Cham.

Hochbaum DS (2016) A polynomial time repeated cuts algorithm for the time cost tradeoff problem: The linear and convex crashing cost deadline problem. Comp \& Ind Eng 95:64-71

Hoek R (2020) Research opportunities for a more resilient postCOVID-19 supply chain - closing the gap between research findings and industry practice. Int J Oper Prod Manag 40(4):341-355

Hosseini S, Morshedlou N, Ivanov D, Sarder M, Barker K, Al Khaled A (2019) Resilient supplier selection and optimal order allocation under disruption risks. Int J Prod Econ 213:124-137

Hosseinia S, Ivanovb D, Dolguic A (2019) Review of quantitative methods for supply chain resilience analysis. Trans Res Part e: Log and Trans Rev 125:285-307

Ivanov D (2021) Lean Resilience: AURA (Active Usage of Resilience Assets) Framework for Post-COVID-19 Supply Chain Management. Int J Log Mgmt

Ivanov D, Dolgui A (2020) OR-methods for coping with the ripple effect in supply chains during COVID-19 pandemic: Managerial insights and research implications. Int J Prod Econ 232. https://doi.org/10. 1016/j.ijpe.2020.107921

Ivanov D, Dolgui A, Sokolov B, Ivanova M (2017) Literature review on disruption recovery in the supply chain. Int J Prod Res 55(20):6158-6174

Ivanov D (2020) Predicting the impacts of epidemic outbreaks on global supply chains: A simulation-based analysis on the coronavirus outbreak (COVID-19/SARS-CoV-2) case. Trans Res Part e: Log Trans Rev 136. https://doi.org/10.1016/j.tre.2020.101922

Jeunet J, Orm MB (2020) Optimizing temporary work and overtime in the Time Cost Quality Trade-off Problem. Eur J Opnl Res 284(2):743-761

Kang C, Choi B-C (2015) An adaptive crashing policy for stochastic timecost tradeoff problems. Computers \& Operations Research 63:1-6

Karmaker C, Ahmed T, Ahmed S, Ali S, Moktadir M, Kabir G (2021) Improving supply chain sustainability in the context of COVID19 pandemic in an emerging economy: Exploring drivers using an integrated model. Sust Prod and Cons 26:411-427

Kazmi S, Baig A, Zia-Ur Rehman M (2018) The Economy of Projects: Analyzing Project Management Resilience, Stress Management and Project Sustainability. Global Econ Rev 3(1):50-61

Lee HG, Yi CY, Lee DE, Arditi D (2015) An Advanced Stochastic TimeCost Tradeoff Analysis Based on a CPM-Guided Genetic Algorithm. Comp-Aided Civ and Infrastructure Engr 30(10):824-842 
Mahmoudi M, Mahdiraji HA, Jafarnejad A, Safari H (2019) Dynamic prioritization of equipment and critical failure modes. Kybernetes 48(9):1913-1941

Mehrjerdi Y, Shafiee M (2021) Shafiee. J Clean Prod 289. https://doi. org/10.1016/j.jclepro.2020.125141

Mensah EK, Asamoah LA, Jafari-Sadeghi V (2021) Entrepreneurial opportunity decisions under uncertainty: recognizing the complementing role of personality traits and cognitive skills. J of Entrp, Mgmnt and Innov 17(1):25-56

Mokhtarzadeh NG, Mahdiraji HA, Beheshti M, Zavadskas EK (2018) A Novel Hybrid Approach for Technology Selection in the Information Technology Industry. Tech 6(1):34

Mulvey J, Vanderbei R, Zenios S (1995) Robust optimization of largescale systems. Oper Res 43(2):264-281

Muriana C, Vizzini G (2017) Project risk management: A deterministic quantitative technique for assessment and mitigation. Int $\mathrm{J}$ Project Manage 35(3):320-340

Nachbagauer AG, Schirl-Boeck I (2019) Managing the unexpected in megaprojects: riding the waves of resilience. Int J Mng Proj Bus 12 (3):694-715

Naderpajouh M, Keeys A, Linkov. (2020a) Resilience in Project Studies: An Interdisciplinary Discourse. Int J Project Manage 38(5):307-309

Naderpajouh N, Matinheikki J, Keeys LA, Aldrich DP, Linkov I (2020b) Resilience and projects: An interdisciplinary crossroad. Proj Ldrshp and Soc 1. https://doi.org/10.1016/j.plas.2020.100001

Nugroho A, Yuliadi B (2018) Sharing Printer Beda Network Menggunakan Jaringan Ad Hoc Dengan Aplikasi Mars Wifi Dan Static Routing Protocol. INOVTEK Polbeng - Seri Informatika 3(2):110

Oeij PR, Gaspersz JB, Van Vuuren T, Dhondt S (2017) Leadership in innovation projects: an illustration of the reflective practitioner and the relation to organizational learning. J Innov Entr 6(1):1-20

Pádár K, Pataki B, Sebestyén Z (2017) Bringing project and change management roles into sync. J Organ Chang Manag 30(5):797-822

Perera HN, Sudusinghe JI (2017, May). Longitudinal analysis of supply chain transformation project management. In 2017 Moratuwa Engineering Research Conference (MERCon) (pp. 153-158). IEEE.

Prasad S, Woldt J, Tata J, Altay N (2019) Application of project management to disaster resilience. Ann Oper Res 283(1-2):561-590

Qin Y, Xiao X, Wigneron JP, Ciais P, Brandt M, Fan L, Li X, Crowell S, Wu X, Doughty R, Zhang Y (2021). Carbon loss from forest degradation exceeds that from deforestation in the Brazilian Amazon. Nature Climate Change 1-7.

Rahi K (2019) Project resilience: A conceptual framework. Int J Inf Syst Proj Manag 7(1):69-83

Rezapour S, Farahani RZ, Pourakbar M (2017) Resilient supply chain network design under competition: A case study. Eur J Opnl Res 259(3):1017-1035

Sabouhi F, Pishvaee M, Jabalameli M (2018) Resilient Supply Chain Design under Operational and Disruption Risks Considering. Comput Ind Eng 126:657-672

Shahriari M (2016) Multi-objective optimization of discrete time-cost tradeoff problem in project networks using non-dominated sorting genetic algorithm. J of Ind Eng Int 12(2):159-169

Shahsavari Pour N, Modarres M, Tavakkoli-Moghaddam R (2012) Time-Cost-Quality Trade-off in Project Scheduling with Linguistic Variables. World Appl Sci J 18(3):404-413

Sharma A, Adhikary A, Bikash Borah S (2020) Covid-19's impact on supply chain decisions: Strategic insights from NASDAQ 100 firms using Twitter data. J Bus Res 117:443-449
Singh S, Kumar R, Panchal R, Tiwari M (2020) Impact of COVID-19 on logistics systems and disruptions in food supply chain. Int J Prod Res. https://doi.org/10.1080/00207543.2020.1792000

Smith AD, Offodile OF (2007) Exploring forecasting and project management characteristics of supply chain management. Int J Log Syst Mgmt 3(2):174

Son J, Hong T, Lee S (2013) A Mixed (Continuous + Discrete) TimeCost Trade-Off ModelConsidering Four Different Relationships with Lag Time. KSCE J Civ Eng 17(2):281-291

Sukumar A, Jafari-Sadeghi V, Garcia-Perez A, Dutta DK (2020) The potential link between corporate innovations and corporate competitiveness: evidence from IT firms in the UK. J Knowl Manag 24(5):965-983

Taghavifard MT, Amoozad Mahdiraji H, Alibakhshi AM, Zavadskas EK, Bausys R (2018) An Extension of Fuzzy SWOT Analysis: An Application to Information Technology. Info 9(3):46

Thomé A, Scavarda L, Scavarda A, de Souza Thomé F (2016) Similarities and contrasts of complexity, uncertainty, risks, and resilience in supply chains and temporary multi-organization projects. Int $\mathrm{J}$ Project Manage 34(7):1328-1346

Todt G, Weiss M, Hoegl M (2019) Leading Through Innovation Project Setbacks: How Authentic Leaders Keep Their Innovators Resilient. Proj Mgmnt J 50(4):409-417

Torabi Yeganeh F, Zegordi S (2020) A multi-objective optimization approach to project scheduling with resiliency criteria under uncertain activity duration. Ann Oper Res 285(1-2):161-196

Tran DH, Cheng MY, Cao MT (2015) Hybrid multiple objective artificial bee colony with differential evolution for the time-cost-quality tradeoff problem. Knowledge-Based Sys 74:176-186

Tran DH, Chou JS, Luong DL (2019). Multi-objective symbiotic organisms optimization for making time-cost tradeoffs in repetitive project scheduling problem. J Civil Engr and Mgmnt 25(4), 322-339.

Tran DH, Long LD (2018) Project scheduling with time, cost and risk trade-off using adaptive multiple objective differential evolution. Engineering,Const and Archt Mgmnt 25(5):623-638

Ulrich D, Yeung A (2019) Agility: the new response to dynamic change. Strateg HR Rev 18(4):161-167

Wang B, Liu Y, Qian J, Parker S (2021) Achieving Effective Remote Working During the COVID-19 Pandemic: A Work Design Perspective. Appl Psychol 70(1):16-59

Wied M, Koch-Ørvad N, Welo T, Oehmen J (2020) Managing exploratory projects: A repertoire of approaches and their shared underpinnings. Int J Project Manage 38(2):75-84

Wood DA(2017) Gas and oil project time-cost-quality tradeoff: Integrated stochastic and fuzzy multi-objective optimization applying a memetic, nondominated, sorting algorithm. J Nat Gas Sci Engr 45:143-164

Wong C, Lirn T, Yang C, Shang K (2020) Supply chain and external conditions under which supply chain resilience pays: An organizational information processing the orization. Int J Prod Econ 226. https://doi.org/10.1016/j.ijpe.2019.107610

Wysocki KR (2013) Effective project management: traditional, agile, extreme (Seventh, Edition. John Wiley \& Sons Inc., Indianapolis, Indiana

Yang Z, Wang Z (2010) Comparison between AON and AOA network diagrams. 2010 IEEE 17Th International Conference on Industrial Engineering and Engineering Management (pp. 1507-1509). Xiamen: IEEE.

Publisher's Note Springer Nature remains neutral with regard to jurisdictional claims in published maps and institutional affiliations. 